\title{
Pneumococcal empyema and complicated pneumonias: global trends in incidence, prevalence, and serotype epidemiology
}

\author{
M. A. Fletcher • H.-J. Schmitt • M. Syrochkina • \\ G. Sylvester
}

Received: 25 November 2013 / Accepted: 15 January 2014 / Published online: 23 February 2014

(C) Springer-Verlag Berlin Heidelberg 2014

\begin{abstract}
This review evaluates the serotype epidemiology of complicated pneumococcal pneumonia (CPP) during the period 1990-2012. PubMed and EMBASE were searched using the terms "empyema", "complicated pneumonia", "pleural infection", "necrotizing pneumonia", "pleural effusion", "parapneumonic effusion", "pneumatocele", or "lung abscess"; "pneumococcal" or "Streptococcus pneumoniae"; and "serotype" for studies on the epidemiology of complicated pneumonias published from January 1, 1990 to October 1, 2013. Studies with data on incidence and serotypes were included; reviews, case reports, and conference abstracts were excluded. Of 152 papers, 84 fitted the inclusion criteria. A few pneumococcal serotypes were predominant causes of CPP, particularly serotypes $1,19 \mathrm{~A}, 3,14$, and 7F. CPP was a more common manifestation of pneumococcal disease among older $(>2$ years old) than younger children. The data support increases in both reported incidence rates and proportions of CPP in children and adults during the period 1990-2012; specific increases varied by geographic region. The proportions of serotype 3 and, particularly in Asia, serotype 19A CPP have increased, whereas most studies show declines in serotype 14. Serotype 1 has been a predominant cause of CPP since 1990, while antibiotic resistance was infrequent among serotype 1 isolates. The reported incidence and proportions of CPP among pneumonia cases steadily increased from 1990 to
\end{abstract}

M. A. Fletcher $(\square) \cdot$ H.-J. Schmitt

Pfizer, Inc., 23-25, avenue du Dr Lannelongue, 75668 Paris Cedex

14, France

e-mail: mark.a.fletcher@pfizer.com

M. Syrochkina

Pfizer, Inc., Yekaterinburg, Russia

G. Sylvester

Pfizer Inc., Collegeville, PA, USA
2012. Several factors might account for these increases, including enhanced disease detection due to a higher index of suspicion, more sophisticated diagnostic assays, and changes in the prevalence of serotypes with capacity to invade the pleural space that were not targeted by the 7-valent pneumococcal conjugate vaccine (PCV7).

\section{Introduction}

Streptococcus pneumoniae is the most common cause of pneumonia in children and a major cause of pneumonia in adults worldwide [1,2]. Among patients with pneumonia, as many as half may develop pleural effusions (i.e., fluid in the pleural space); of these, 5-10\% may progress to empyema [3]. In general, "complicated pneumonia" refers to pneumonia accompanied by pleural effusion. Empyema is a serious complication characterized by pus and bacteria in the pleural space $[3,4]$, which may progress to necrosis, cavitation, or fistulas in the thoracic cavity. S. pneumoniae is the most common cause of complicated pneumonia in children and a common cause in adults $[5,6]$. Other bacteria associated with acute complicated pneumonias include $S$. pyogenes, S. milleri, Staphylococcus aureus, Haemophilus influenzae, Mycoplasma pneumoniae, Pseudomonas aeruginosa, other Streptococcus species, and, less commonly, Klebsiella, Enterobacter, Proteus, Salmonella, and Yersinia species [5].

The reported incidence and proportion of cases of complicated pneumococcal pneumonia (CPP) in children and adults have increased in recent decades [7-19]. This trend has been described both before and after the introduction in 2000 of the 7-valent pneumococcal conjugate vaccine (PCV7; serotypes 4, $6 \mathrm{~B}, 9 \mathrm{~V}, 14,18 \mathrm{C}, 19 \mathrm{~F}$, and $23 \mathrm{~F}$ conjugated to $\mathrm{CRM}_{197}$ ) for pediatric vaccination. A 23 -valent pneumococcal polysaccharide vaccine (PPV23) containing pneumococcal capsular polysaccharides (serotypes 1, 2, 3, 4, 5, 6B, 7F, 8, 9N, 9V, 
10A, 11A, 12F, 14, 15B, 17F, 18C, 19A, 19F, 20, 22F, 23F, and 33F) was introduced in 1983 for the vaccination of children and adolescents at high risk of pneumococcal disease, but primarily older adults. Unlike the pneumococcal conjugate vaccines, PPV23 is not approved for children aged $<2$ years. PPV23 in adults has been shown to have an impact on bacteremic pneumococcal pneumonia, but not all-cause pneumonia [20,21]. More recently, the 10-valent pneumococcal conjugate vaccine (PCV10; serotypes 1, 4, 5, 6B, 7F, 9V, 14 , and $23 \mathrm{~F}$ conjugated to non-typeable $H$. influenza protein $\mathrm{D}$, serotype $18 \mathrm{C}$ conjugated to tetanus toxoid, and serotype 19F conjugated to diphtheria toxoid) and the 13-valent pneumococcal conjugate vaccine (PCV13; serotypes 1, 3, 4, 5, 6A, $6 \mathrm{~B}, 7 \mathrm{~F}, 9 \mathrm{~V}, 14,18 \mathrm{C}, 19 \mathrm{~A}, 19 \mathrm{~F}$, and $23 \mathrm{~F}$ conjugated to $\mathrm{CRM}_{197}$ ) were introduced beginning in 2009 (Table 1).

A limited number of pneumococcal serotypes have been associated with CPP and pneumococcal empyema (PnEmp). Changes in the serotype epidemiology of invasive pneumococcal disease (IPD) and pneumococcal pneumonia have been reported in recent years, with significant declines in incidence and in the proportion of disease caused by PCV7 serotypes and increases in the proportion of non-PCV7 serotype disease [22-27]. Although these changes are suggestive of serotype replacement, similar trends have also been reported in some countries prior to the introduction of PCV7 [28, 29, 68].

The purpose of this review is to evaluate the serotype epidemiology of CPP during the period 1990-2012.

\section{Methods}

PubMed and EMBASE were searched for studies on the epidemiology and incidence of CPP published from January 1, 1990 through October 1, 2013 using the terms: "empyema", "complicated pneumonia", "pleural infection", "necrotizing pneumonia", "pleural effusion", "parapneumonic effusion", "pneumatocele", or "lung abscess"; "pneumococcal" or "Streptococcus pneumoniae"; and "serotype". Studies with data on incidence, prevalence (i.e., proportion of cases), or serotypes were included; reviews, case reports, and conference abstracts were excluded. In addition, the references sections of relevant review articles were checked for studies not identified during the online search.

The base population used for analyses varied by study. For example, among studies of incidence or proportion of complicated pneumonias or empyema, the base populations included: hospitalized patients [13] or hospitalized patients with community-acquired pneumonia (CAP) [19, 30-32]; pneumococcal pneumonia $[9,16,32-40]$; IPD $[10,12,17,18$, 41-49]; complicated pneumonia [7, 13, 50-54]; complicated pneumonia with positive cultures [14]; CPP [55]; empyema [56-61]; or empyema with fistula [62].
Table 1 Pediatric pneumococcal conjugate vaccine approval history for the countries included in this review (Pfizer, data on file)

\begin{tabular}{|c|c|c|}
\hline Country & Vaccine & $\begin{array}{l}\text { Start of the } \\
\text { immunization } \\
\text { program }^{\text {a }}\end{array}$ \\
\hline
\end{tabular}

North America

Canada

PCV7

$2001^{\mathrm{b}}$

USA

PCV13

2010

PCV7

2000

PCV13

2010

South America

Mexico

PCV7

2007

Uruguay

PCV13

2010

PCV7

2008

PCV13

2010

Europe

France

PCV7

2006

Germany

PCV13

2010

PCV7

$2006^{\mathrm{c}}$

PCV10

$2009^{\mathrm{c}}$

Italy

PCV13

$2009^{\mathrm{c}}$

PCV7

2005-2007

PCV13

2010

Portugal

PCV7

$2006^{\mathrm{d}}$

PCV13

2009

Spain

PCV7

$2002-2006^{\mathrm{d}}$ 2006-2009

$2010^{\mathrm{b}}$

Turkey

PCV13

2008

PCV7

2011

UK

PCV7

2006

PCV13

2010

Middle East/North Africa

Israel

PCV7

2009

PCV13

$2010^{\mathrm{e}}$

\section{Asia-Pacific}

Australia

PCV7

$2001^{\mathrm{f}}$

China

PCV13

2010

PCV7

$2008^{\mathrm{g}}$

PCV13

No

India

PCV7

$2010^{\mathrm{d}}$

PCV13

$2012^{\mathrm{d}}$

Philippines

PCV7

No

PCV10

2012

PCV13

2013

Singapore

PCV7

No

PCV13

2011

South Korea

PCV7

$2003^{\mathrm{d}}$

PCV13

$2010^{\mathrm{d}}$

Taiwan

PCV13 
Table 1 (continued)

\begin{tabular}{lll}
\hline Country & Vaccine & $\begin{array}{l}\text { Start of the } \\
\text { immunization } \\
\text { program }^{\mathrm{a}}\end{array}$ \\
\hline Vietnam & PCV7 & No \\
PCV13 & No \\
\hline
\end{tabular}

PCV7, 7-valent pneumococcal conjugate vaccine; PCV10, 10-valent pneumococcal conjugate vaccine; PCV13, 13-valent pneumococcal conjugate vaccine

${ }^{a}$ Dates refer to a national immunization program, unless otherwise specified

${ }^{\mathrm{b}}$ Year of introduction into immunization programs varied by province

${ }^{\mathrm{c}}$ Physician choice program

${ }^{\mathrm{d}}$ Private market only

${ }^{\mathrm{e}}$ Switched to PCV13 in November 2010

${ }^{\mathrm{f}}$ Included in the national immunization program in 2005

${ }^{\mathrm{g}}$ Regional (city) mass vaccination programs

Some studies described the clinical methodologies used to identify pleural effusion or empyema prior to microbiological identification. Retrospective studies used: diagnostic coding $[16,19,30,31,35,52,61]$; records of chest radiographs $[9$, $33,48,50]$; computed tomography (CT) $[7,9,34,50]$; ultrasound [7, 34, 50, 56]; microbiologic culture records [13]; or results at surgery [56]. One study reviewed "pleural effusion data", although no other details were specified [48]. Prospective studies used: thoracocentesis [39, 51, 53, 54]; CT, ultrasound, or chest radiograph plus clinical signs [58]; CT, ultrasound, or chest radiograph [32]; or physical examination and chest radiograph $[37,60,63]$. One study did not specify the diagnostic methodology [49].

Studies varied in the methodologies used to isolate S. pneumoniae, including: culture of samples from the pleural cavity [7, 13, 49-51, 54, 58, 62, 64-66], blood [32, 68-71], blood and pleural cavity $[9,10,14,15,17,18,30,31,34-36$, $38,41-48,52,53,56,57,63,72-90]$, or unspecified sites [33, 40, 91]; and, more recently, investigators used polymerase chain reaction (PCR) or real-time PCR to identify pneumococcal-specific genes (e.g., ply, LytA, rpoB, or wzg $[\operatorname{cps} A])$ in samples from the pleural cavity $[43,46,49,51$, 53-55, 58, 60, 64, 67, 87, 88, 90, 92-94], blood [15, 32, 37, $75,95]$, blood and pleural cavity [88], or nasopharyngeal aspirate [96]. A few studies applied immunochromatographic pneumococcal antigen detection (Binax NOW ${ }^{\circledR}$ ) from blood or urine $[15,38,51,74,77,84]$.

Pneumococcal serotypes in blood or pleural fluid were identified with the Quellung reaction (also referred to as capsular swelling) $[7,12,14,15,17,18,30,31,34-38,40$, 42-49, 56, 68, 69, 71, 73, 77, 82, 85-88, 90-93], dot blot [47, $71,93]$, slide or latex agglutination $[8-10,40,63,65,70,72$, $77,80,81,83,84,97,98]$, enzyme-linked immunoassays [55, 99], real-time PCR [32, 37, 43, 44, 46, 49, 51, 64, 65, 87, 88,
90, 93, 95], or multiplex PCR [54, 58, 60, 67, 74, 84, 92, 94, 97]. The Quellung reaction may include up to all the known serotypes, whereas PCR is typically more limited in the serotypes that can be identified. Some studies used more than one methodology (e.g., initial serotyping of cultured isolates, followed by PCR in culture-negative samples) $[37,65,87$, 88, 93, 94].

Definitions of penicillin susceptibility varied; some studies used breakpoints established by the Clinical and Laboratory Standards Institute (CLSI) in 2009 [53, 74, 83, 88, 90, 100], whereas others used pre-2009 breakpoints $[7,9,15,17,30$, $34,63,73]$.

\section{Results}

A total of 152 papers were initially identified; 68 were excluded because there were no data on incidence or serotypes, or they were case reports; consequently, 84 were included in this analysis.

Table 2 presents data on the incidence and proportion of CPP [7, 9, 10, 12-14, 16-19, 30-47, 49-62]. Trends and agerelated differences in the studies are discussed below.

\section{Incidence}

The incidence of any-cause empyema among children aged $<19$ years in Utah (USA) (1994-2007) [30, 31] and Australia (1998-2010) [19] ranged from 0.9 to 12.5 per 100,000 population, and tended to increase over time; the incidence was highest in children aged 0-4 years (Table 2) [19]. Likewise, in Spain from 1997-2001 to 2002-2006, the PnEmp incidence was lower in children aged 5-17 years $(0.5-1.3$ per 100,000 population) as compared to younger children [12]. In 19962001 and 2006-2009, the adult PnEmp incidence was higher in those aged $>65$ years $(3.5-4.8$ per 100,000$)$ than other adult age groups $(0.5-1.8$ per 100,000) (Table 2) [17].

The incidence for PnEmp tended to increase from the late 1990s to the mid-2000s in children in the USA $[10,16]$ and Spain [12], but remained lower in children aged 5-17 years compared with younger children (Table 2) [12]. For example, the PnEmp incidence among children aged $<18$ years in Utah (USA) increased from 10.3 per 100,000 population in 19962000 to 14.3 per 100,000 population in 2001-2003 [10], and increased in children aged 2-4 years in the USA from 1.1 to 2.5 per 100,000 population from 1996-1998 to 2005-2007, respectively [16]. In Spain from 1997-2001 to 2002-2006, the PnEmp incidence increased from 2.2 to 9.2 per 100,000 population in children aged $<2$ years and from 1.5 to 9.2 per 100,000 population in children aged $2-4$ years [12]. Of note, two studies from Spain showed significant declines in the PnEmp incidence following the introduction of PCV13 into the pediatric immunization program: in one, from 6.73 to 4.14 


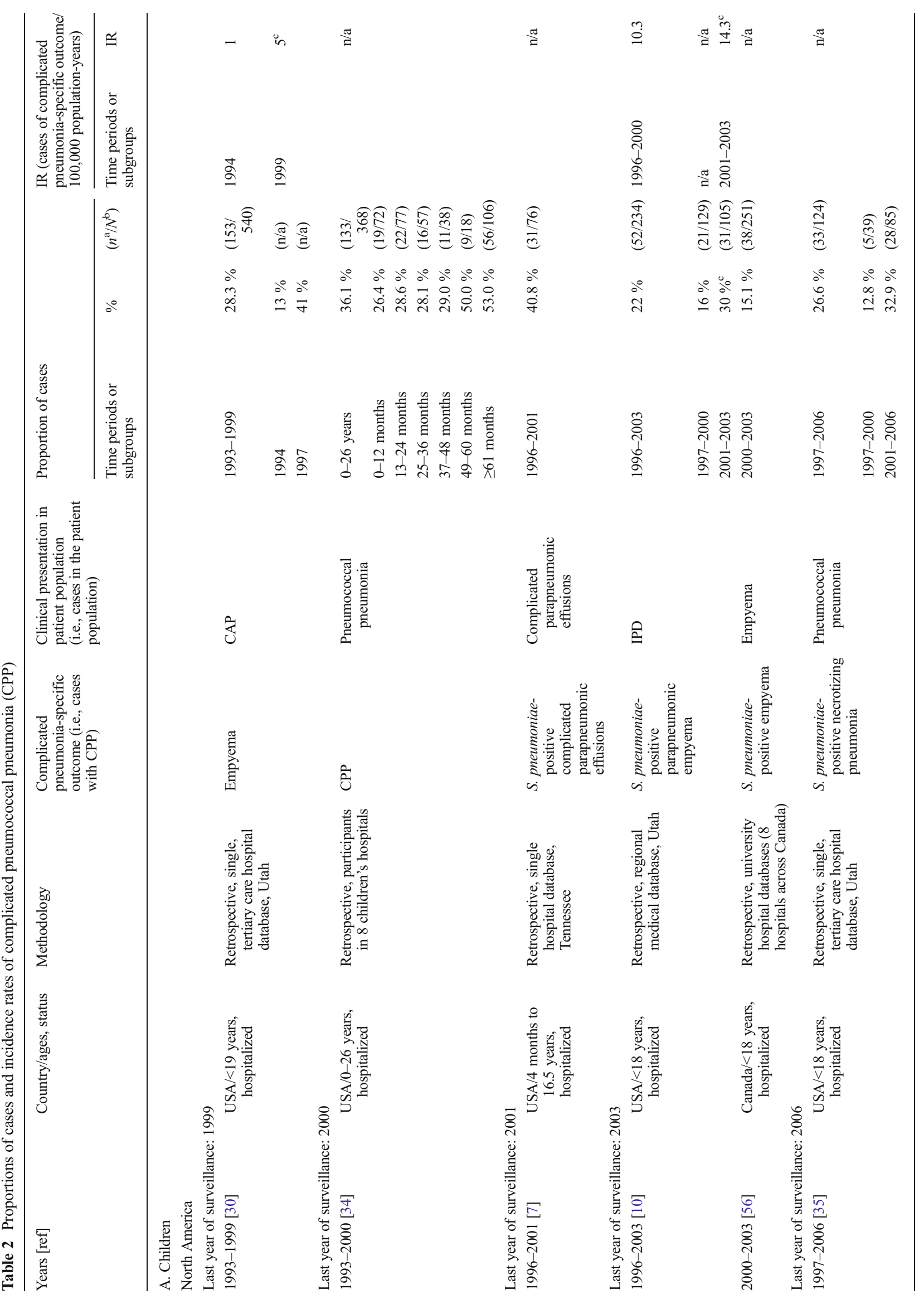




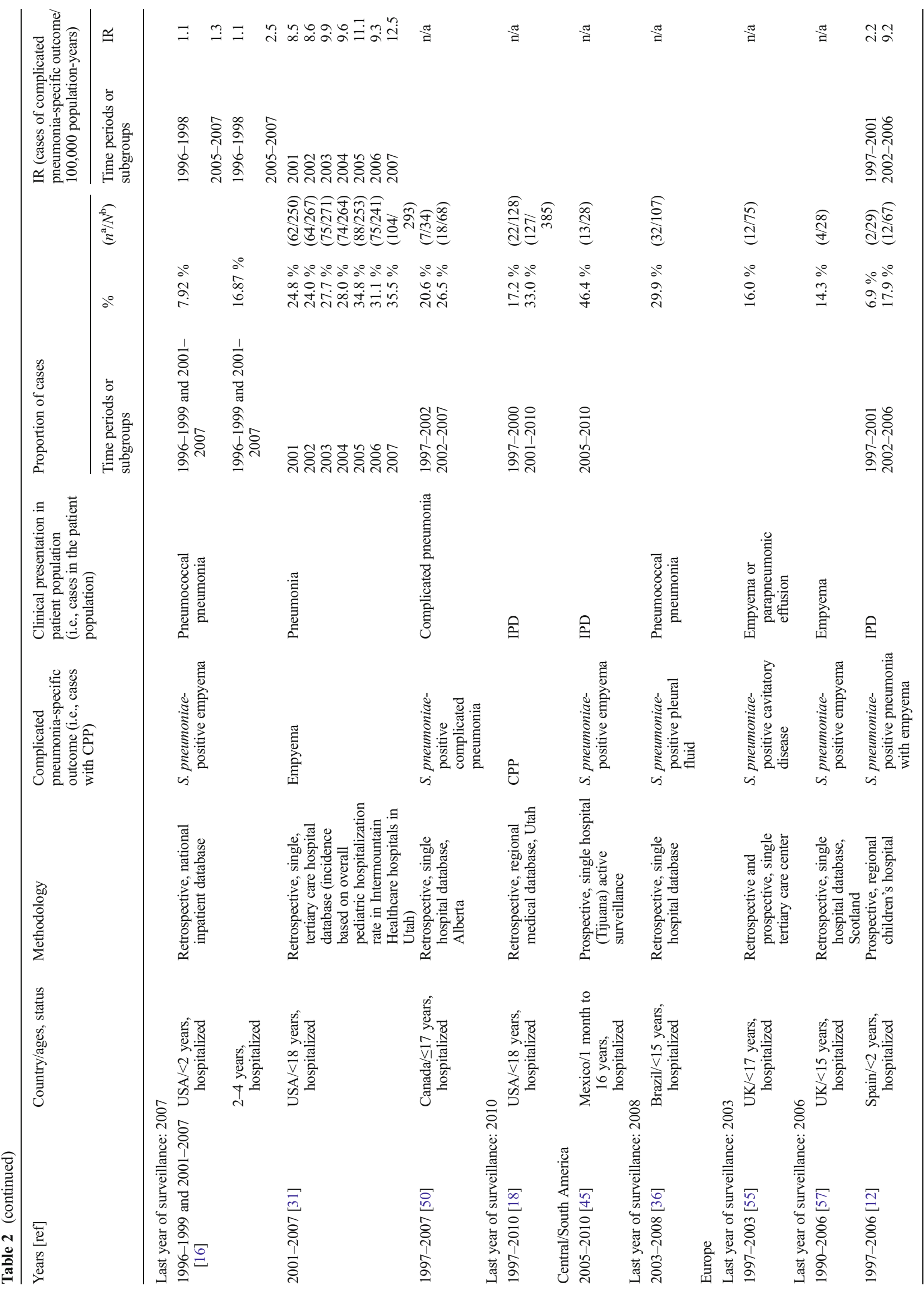




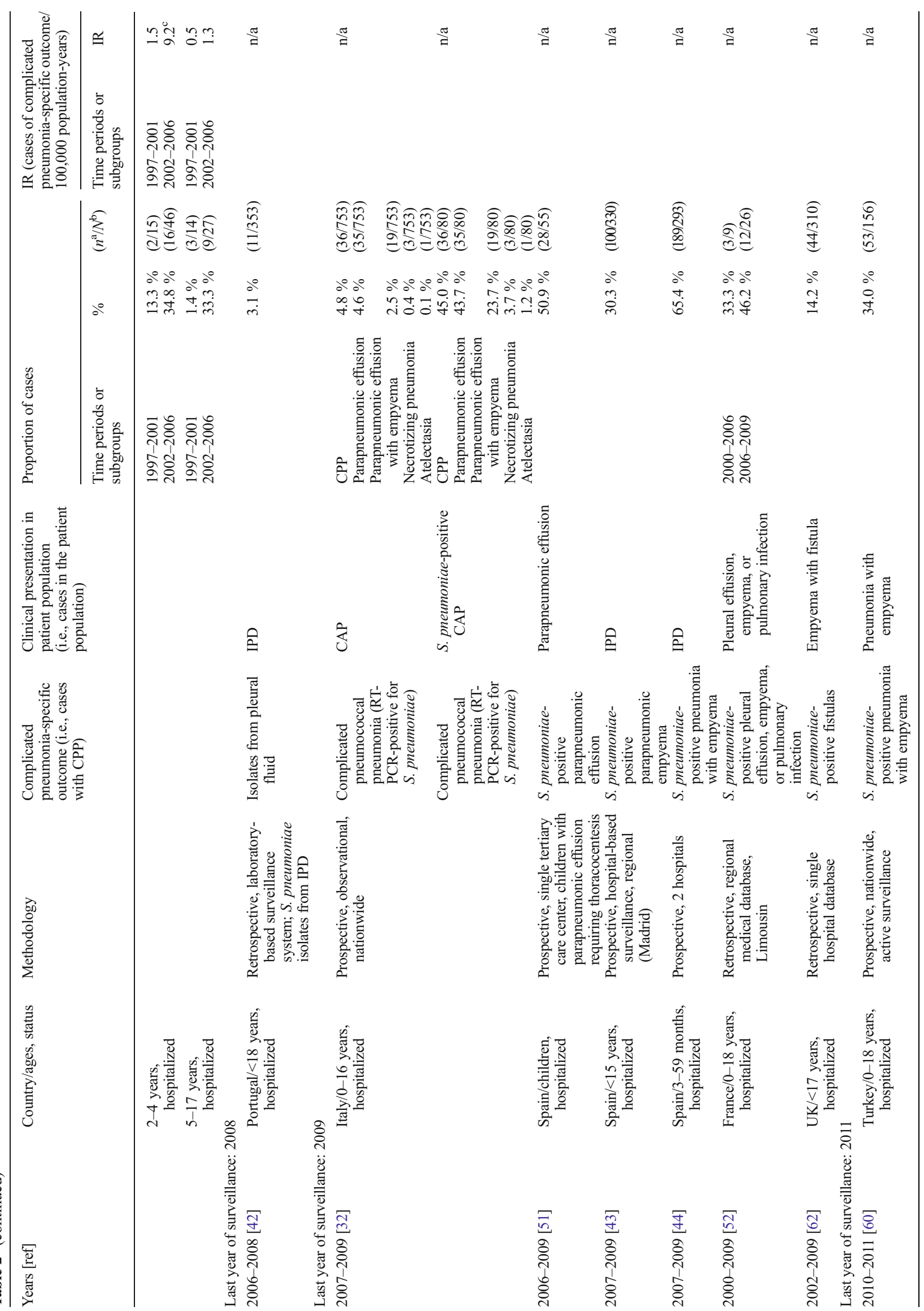




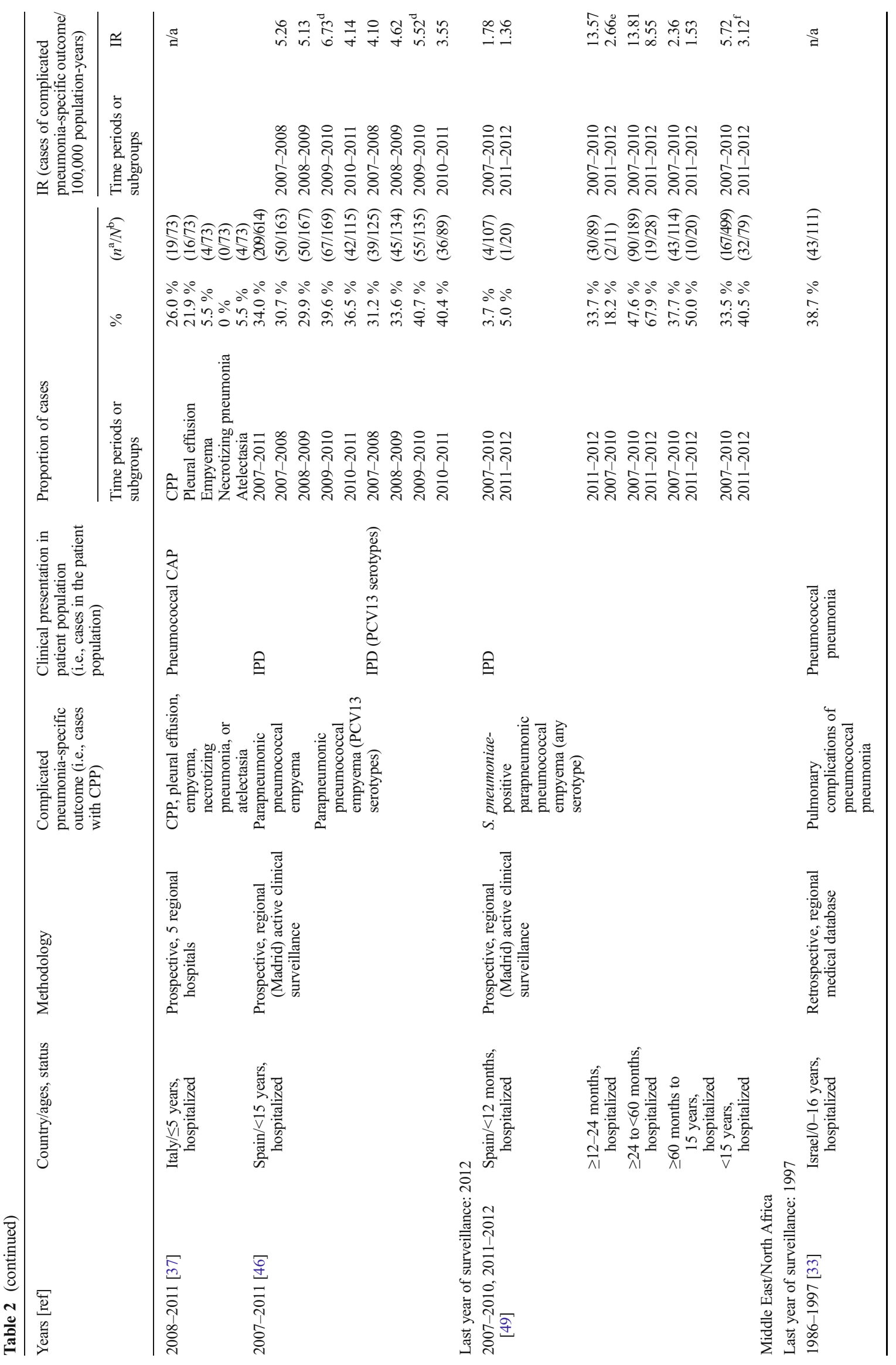




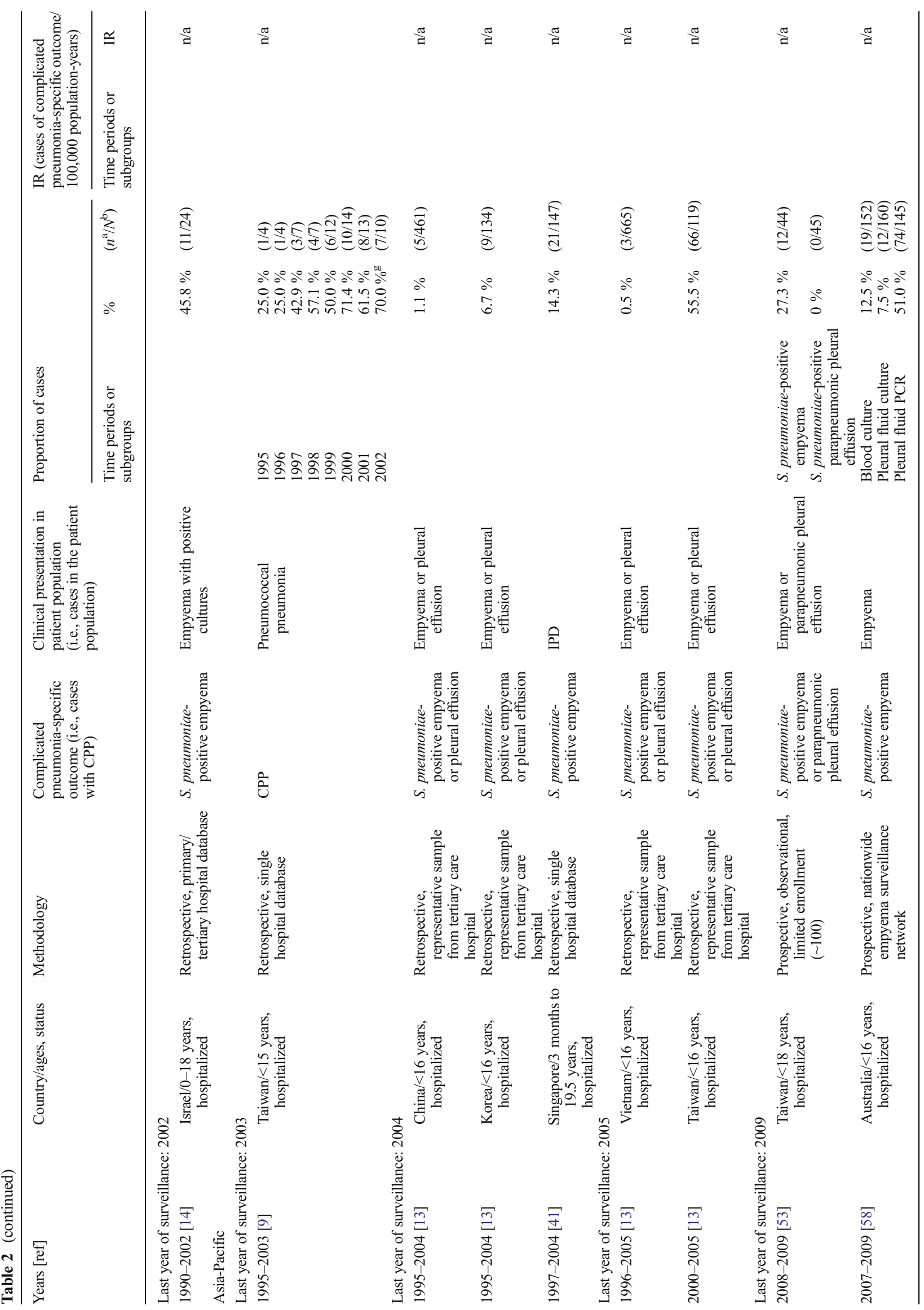




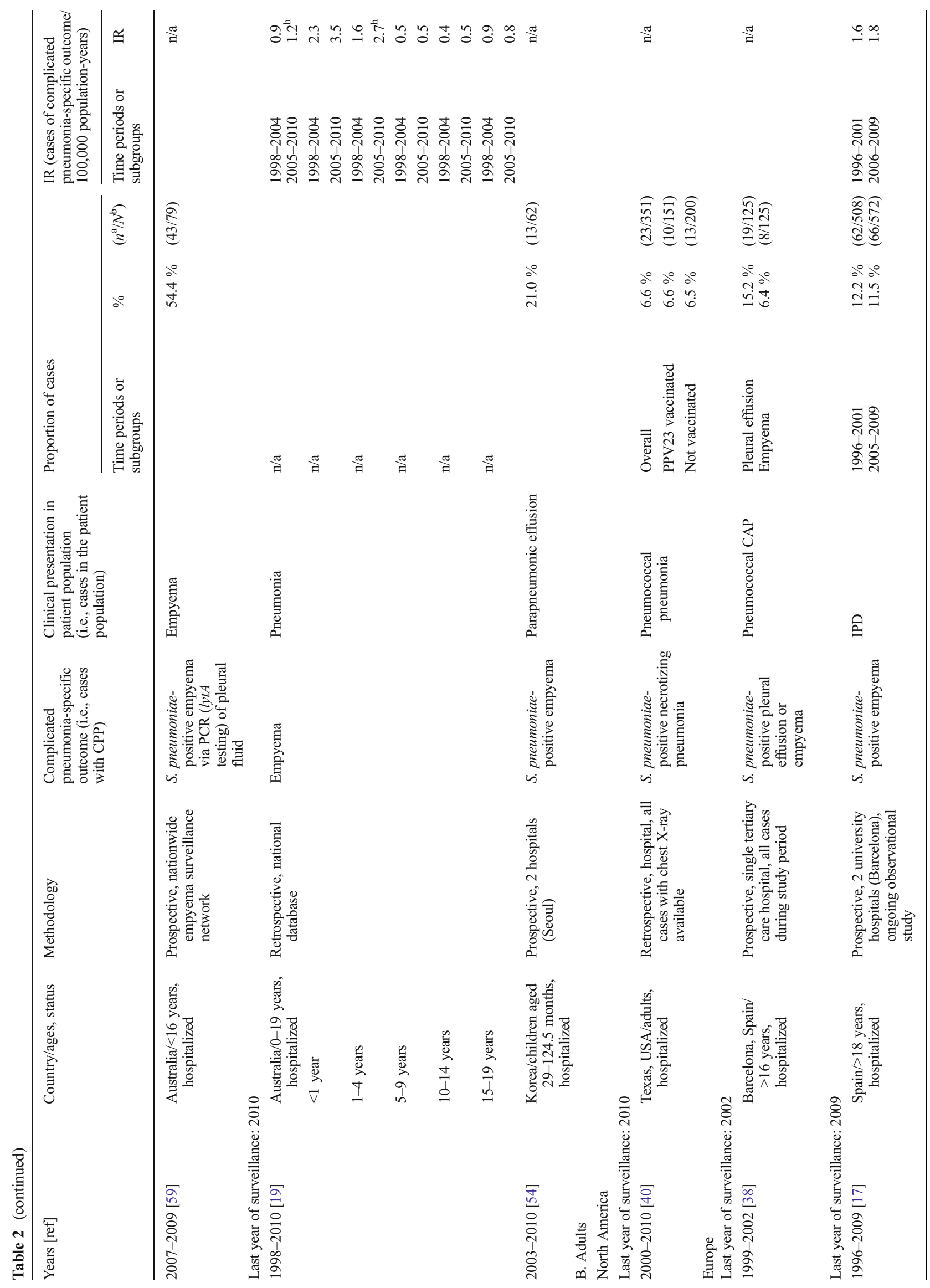




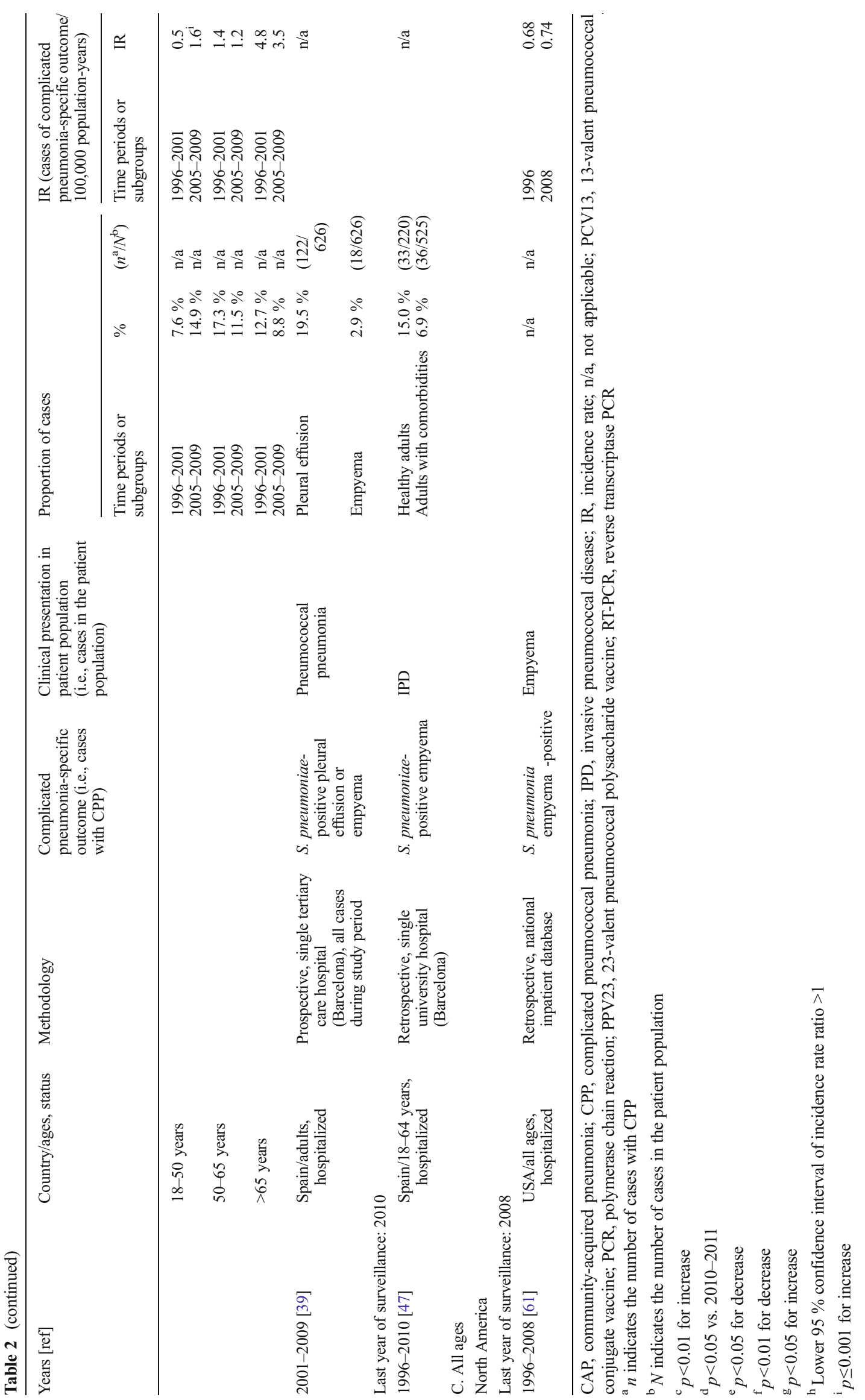


per 100,000 from 2009-2010 to 2010-2011 (age <15 years) [46]; in the other, from 5.72 to 3.12 per 100,000 population from 2007-2010 to 2011-2012 ( $p=0.0019)$ (age $<15$ years) [49], and from 3.57 to 2.66 per 100,000 population ( $p=$ 0.0224 ) (ages $\geq 12$ to $<24$ months) (Table 2) [49].

\section{Proportion of cases with CPP}

Outcomes used as numerators for proportions of cases with CPP ranged from more general (e.g., pulmonary complications, complicated pneumonia) to more specific (e.g., empyema, cavitatory disease). Denominators varied, including hospitalized patients, hospitalized patients with CAP, hospitalized patients with pneumococcal CAP, or children with parapneumonic PnEmp. In addition, the assessment methods varied in sensitivity, which may have affected the reported proportions. For example, in hospitalized children with empyema in Australia, only $7.5 \%$ of pleural fluid cultures, but $51.0 \%$ of pleural fluid PCRs, were pneumococcal-positive [58].

The proportion of cases of CPP or PnEmp among hospitalized children with pneumococcal pneumonia or IPD ranged from 7.9 to $71.4 \%$ (Table 2) and tended to increase over time $[9,10,12,16,18,32-37,41,44-46,49]$. For example, the proportions of cases of CPP or PnEmp in hospitalized children with IPD in Spain increased from $6.9 \%$ in 1997-2001 [12] to $65.4 \%$ during 2007-2009 [10, 18, 41, 44-46, 49]. Among hospitalized children with CAP in Utah (USA), the proportion of cases of complicated pneumonia and empyema increased from $13 \%$ in 1994 to $41 \%$ in 1997 [30]. Among children with complicated pneumonia or empyema, the proportion of cases of PnEmp as reported in several countries ranged from 0 to $54.4 \%$, although the sample sizes were often small $[7,13,14$, $49,50,52-60,62]$.

Among hospitalized adults with pneumococcal CAP, the proportions of cases with pleural effusion (PE) (15.2-19.5\%, Spain) $[38,39]$ were higher than those for PnEmp $(6.4 \%$, Spain) [38] or necrotizing pneumonia (6.5-6.6 \%, USA) [40]. Among hospitalized adults with IPD in Spain, 6.9-15.0 \% were diagnosed with PnEmp (Table 2) [17, 47].

Effect of age on the incidence and proportion of cases of CPP

The effect of age on CPP was not consistent across studies, and age effects for incidence differed as compared to proportion. In most studies, older children comprised a larger proportion of those with CPP or PnEmp relative to other pneumococcal diseases. In Utah (USA) (1997-2010), children with CPP were significantly older than those with other forms of IPD (37 months vs. 25 months; $p<0.001$ ) [18]. Among children with pneumococcal pneumonia in the USA (19932000), the proportion of cases with CPP increased with age from $26.4 \%$ (ages $0-12$ months) to $53.0 \%$ (ages $>61$ months)
[34]. In contrast, in a study of children from four Asian countries (Vietnam, China, Korea, and Taiwan), empyema and PE were most common in the younger age groups, particularly those $\leq 4$ years of age [13].

The pattern of age-specific incidence may differ from that of the proportion of cases. For example, among hospitalized children with IPD in Spain (1997-2006), the proportion of cases with PnEmp increased with age from 6.9-17.9\% (ages $<2$ years) to $21.4-33.3 \%$ (ages 5-17 years), whereas the PnEmp incidence declined with age from 2.2-9.2 per 100,000 population (ages $<2$ years) to $0.5-1.3$ per 100,000 population (ages 5-17 years), which seems to parallel the pattern of IPD incidence among children [12]. In particular, in another study in Spain (2007-2012), the PnEmp incidence was greater among children aged $\geq 24$ to $<60$ months (8.5513.81 per 100,000 population) than among younger ( $<12$ months: $1.78-1.36$ per 100,000 population) or older (5-15 years: $1.53-2.36$ per 100,000 population) children [49].

In Spain (1996-2009), although adults aged 50-65 years had a higher proportion of cases of PnEmp (17.3\%) than adults aged $>65$ years $(12.7 \%)$, the PnEmp incidence was lower among adults aged 50-65 years than those aged $>65$ years ( 1.4 vs. 4.8 per 100,000 population, respectively) [17], which is consistent with the trend of age-specific incidence of IPD with aging.

\section{Serotype epidemiology}

Table 3 presents data on serotype epidemiology [7-9, 14, 15, $17,18,30-35,37,39-41,43,44,46,47,49,51-60,62,64$, 66-69, 72, 73, 75-84, 86-91, 93, 94, 97, 99, 101, 102]. Globally, serotypes 1 and 19A exhibited strong associations with pneumococcal PE [15, 52, 66, 69], PnEmp [10, 31, 43, $46,49,54,57,58,60,68,72,81,83,88,90,93,101]$, or both $[32,39,44]$.

In Utah (USA) (2001-2010), CPP in children was caused mainly by serotypes 1, 7F, 19A, and 3 (Table 3). Compared with other serotypes, serotype 1 was significantly more likely to cause CPP than other pneumococcal diseases ( $86 \%$ vs. $29 \%$; odds ratio [OR], 14.0; $p<0.001)$ [18]. Among children with IPD in Spain (2002-2006), serotype 1 caused $29.6 \%$ of cases of PnEmp, compared with $11.1 \%$ caused by PCV7 serotypes (NB, which were all serotype 14 isolates) (Table 3) [101]. Similarly, among adults during 2006-2009 in Spain, serotype 1 caused $32.7 \%$ of cases of PE [39].

Serotype 19A also appears to be important, particularly in the Asia-Pacific region. For example, serotype 19A caused $69.2 \%$ and $71.0 \%$ of cases of pneumococcal necrotizing pneumonia and PnEmp, respectively, in children in Taiwan [83], 46.2 \% of PnEmp cases in children in Korea [54], and $36.4 \%$ of PnEmp cases in children in Australia [58].

Serotypes varied in their prevalence as complicated versus uncomplicated pneumonia. In children in Utah (USA) (1997- 


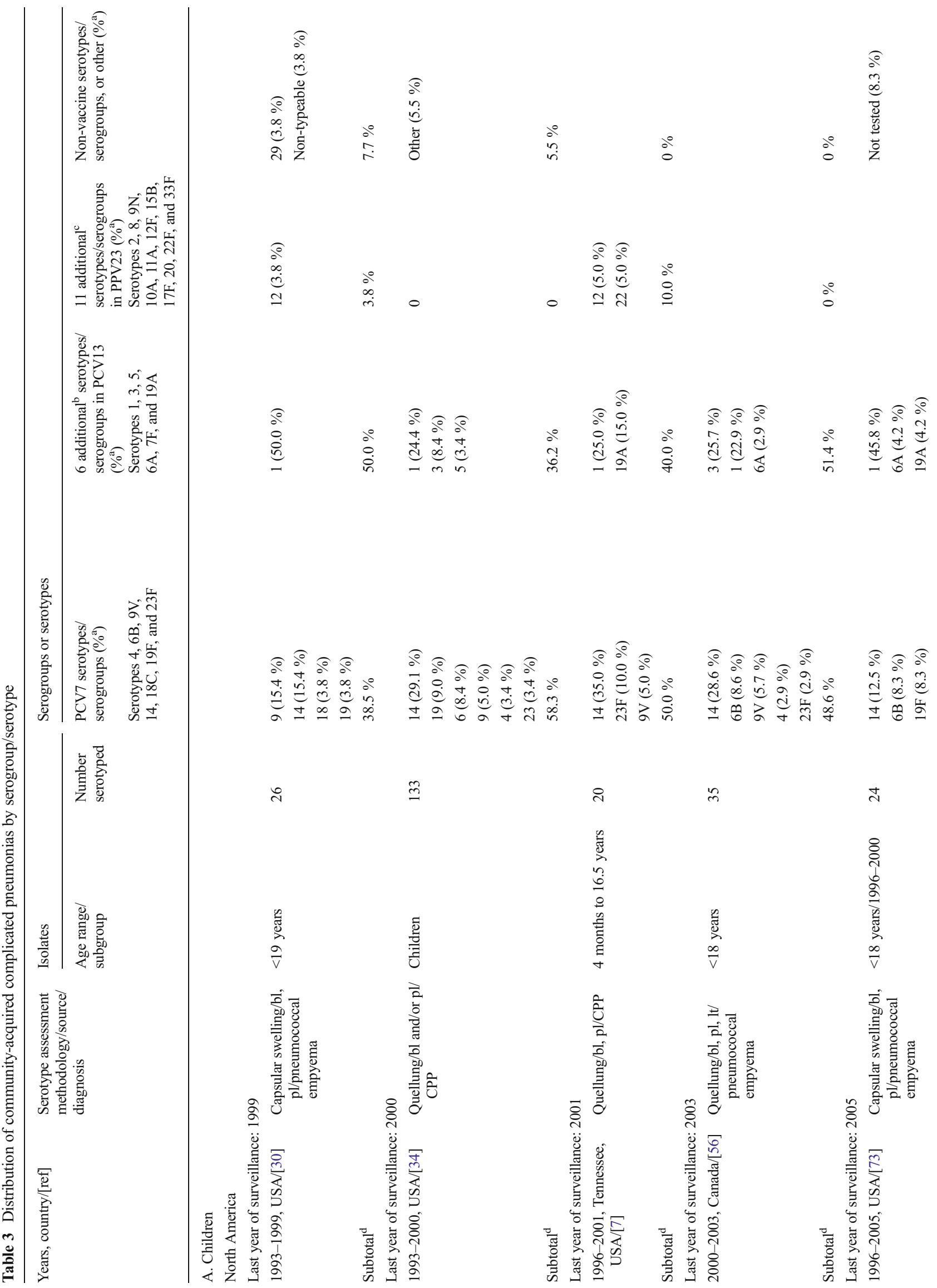




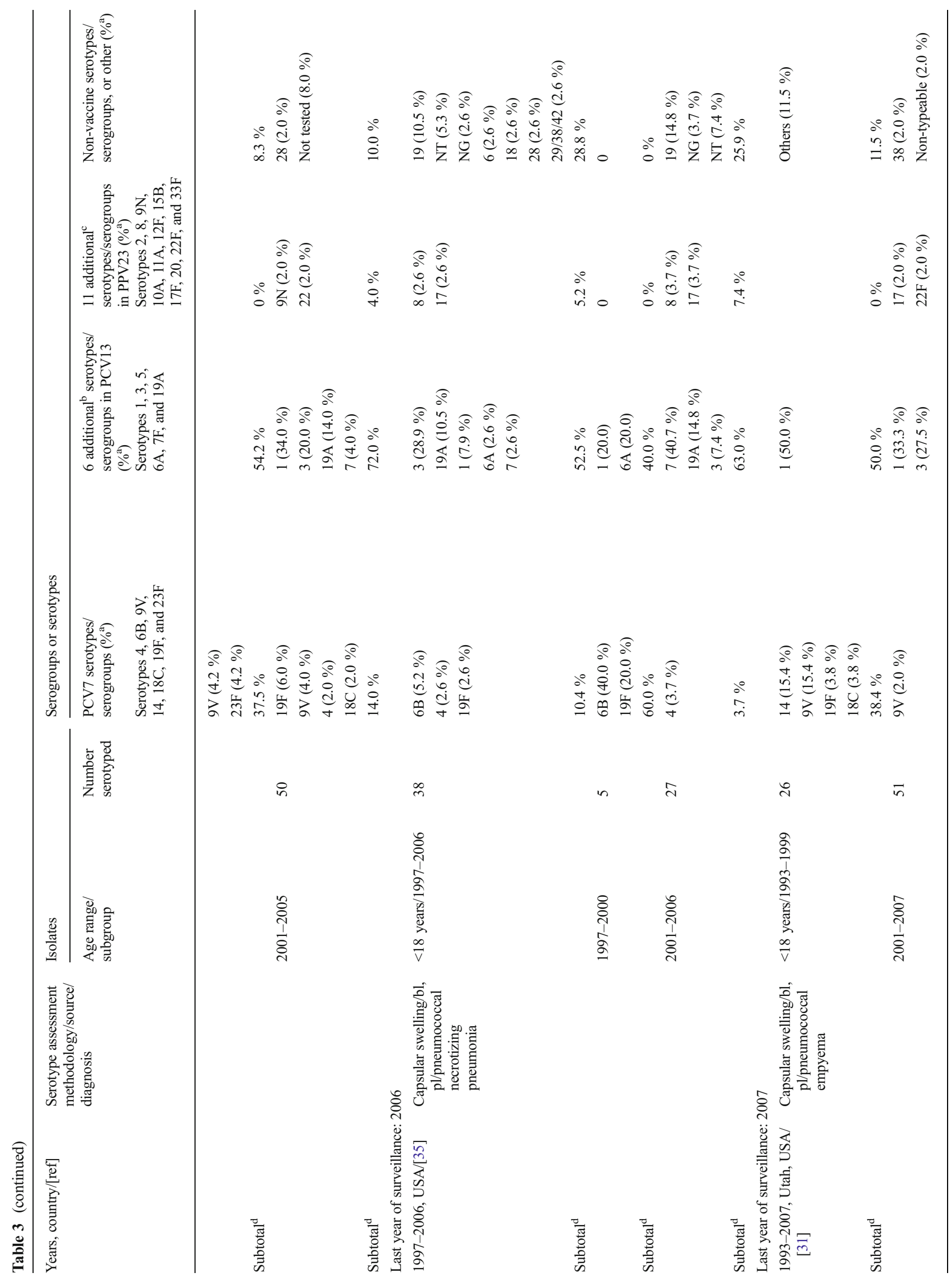




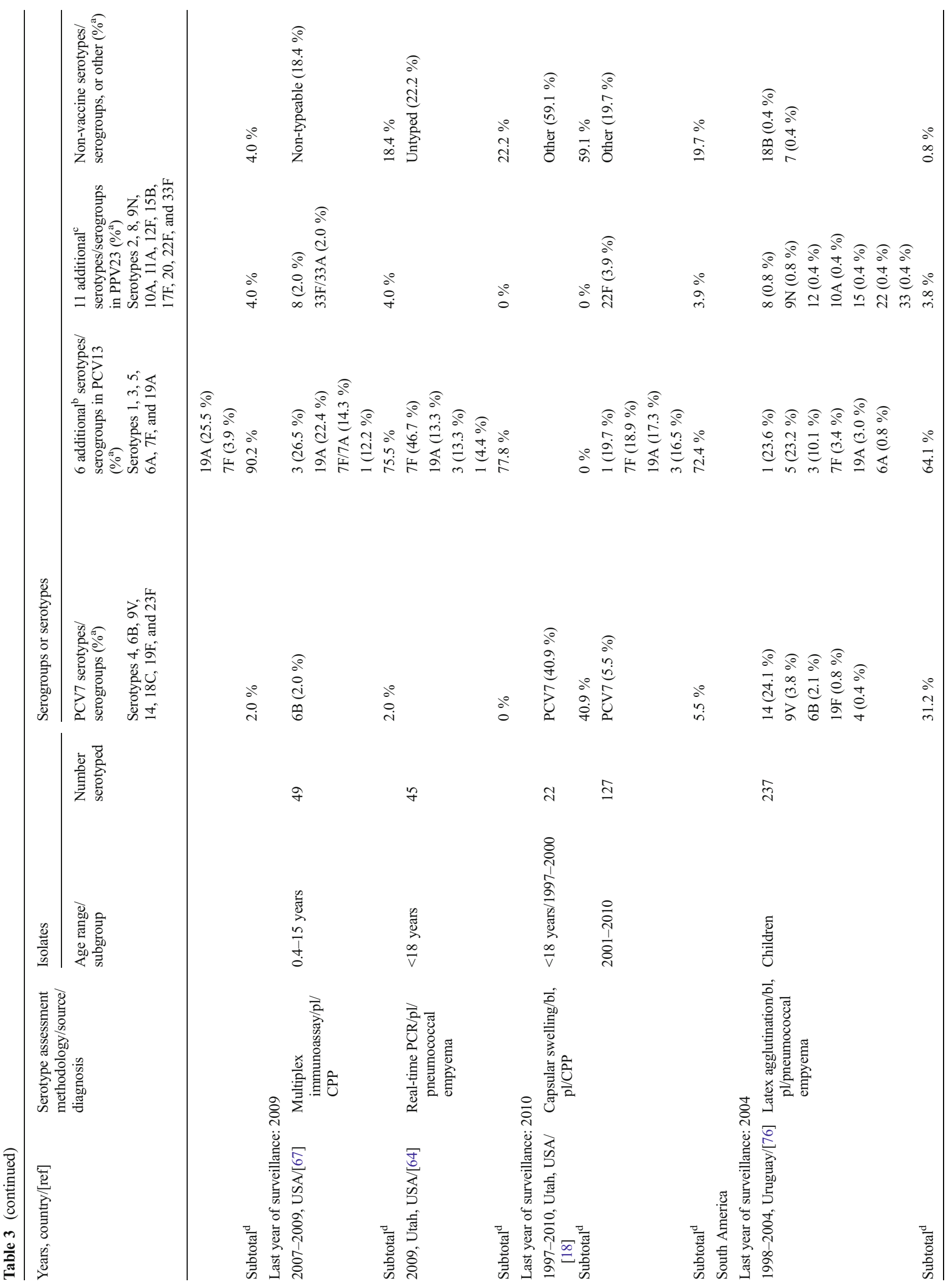




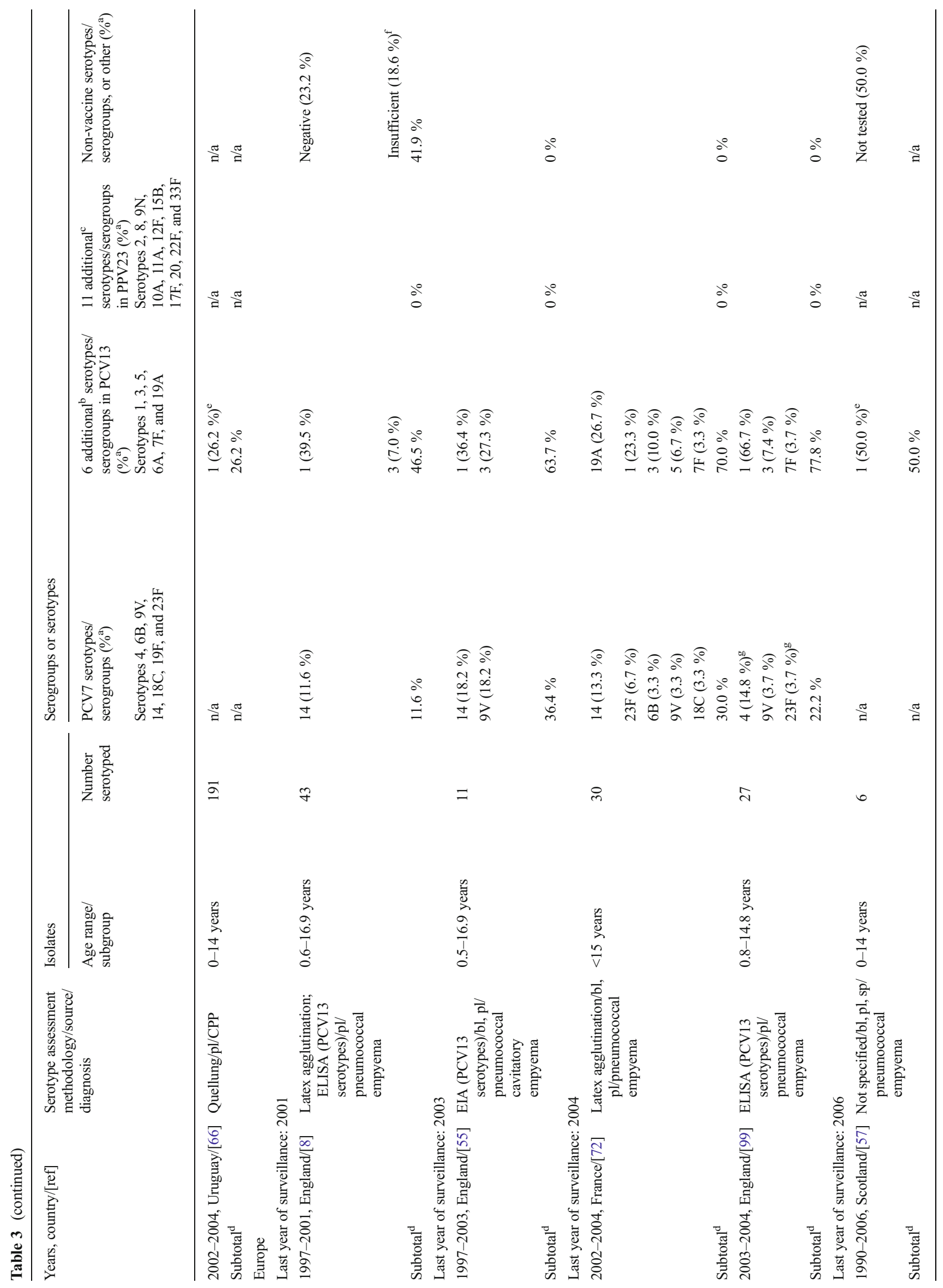




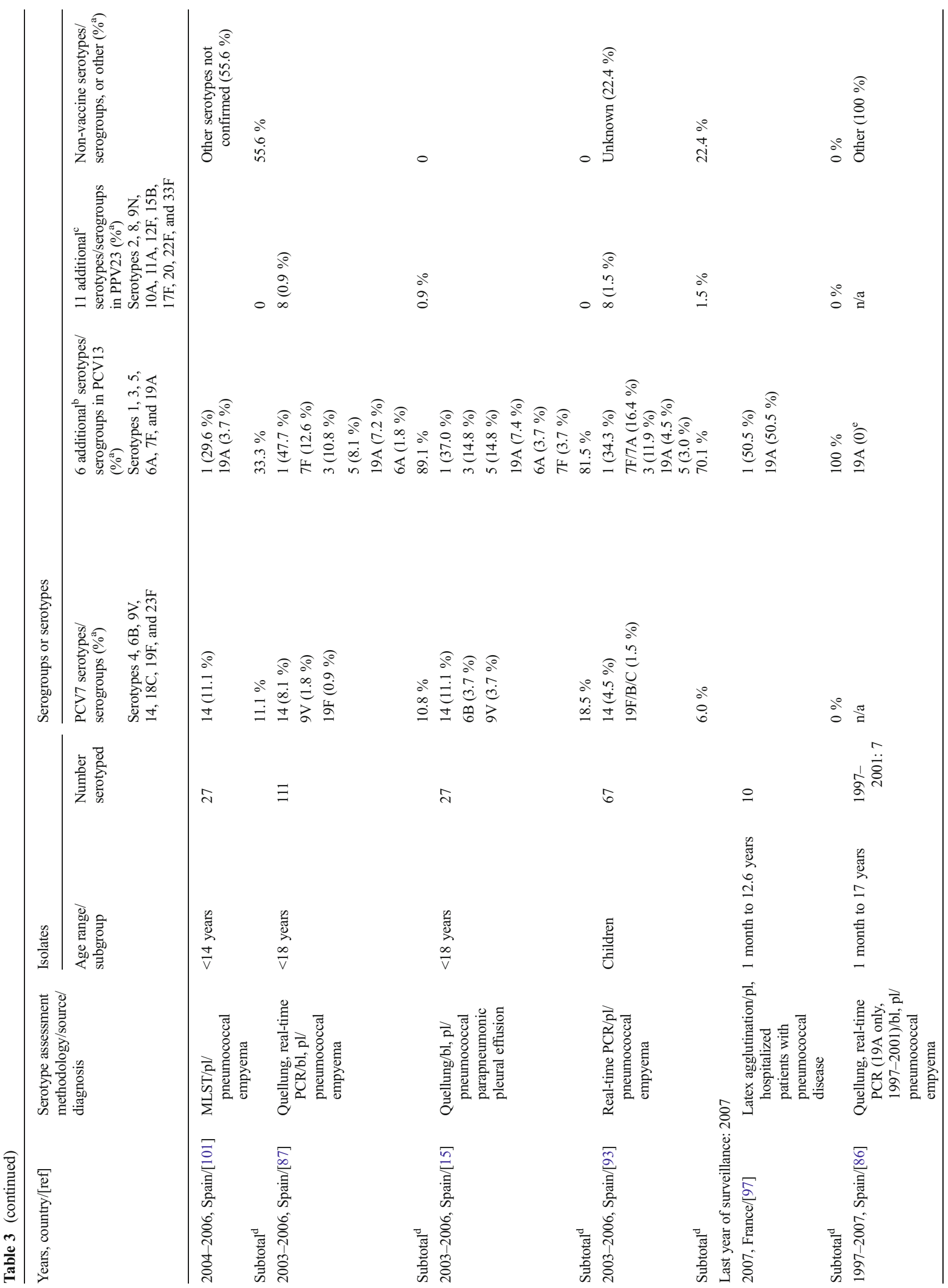




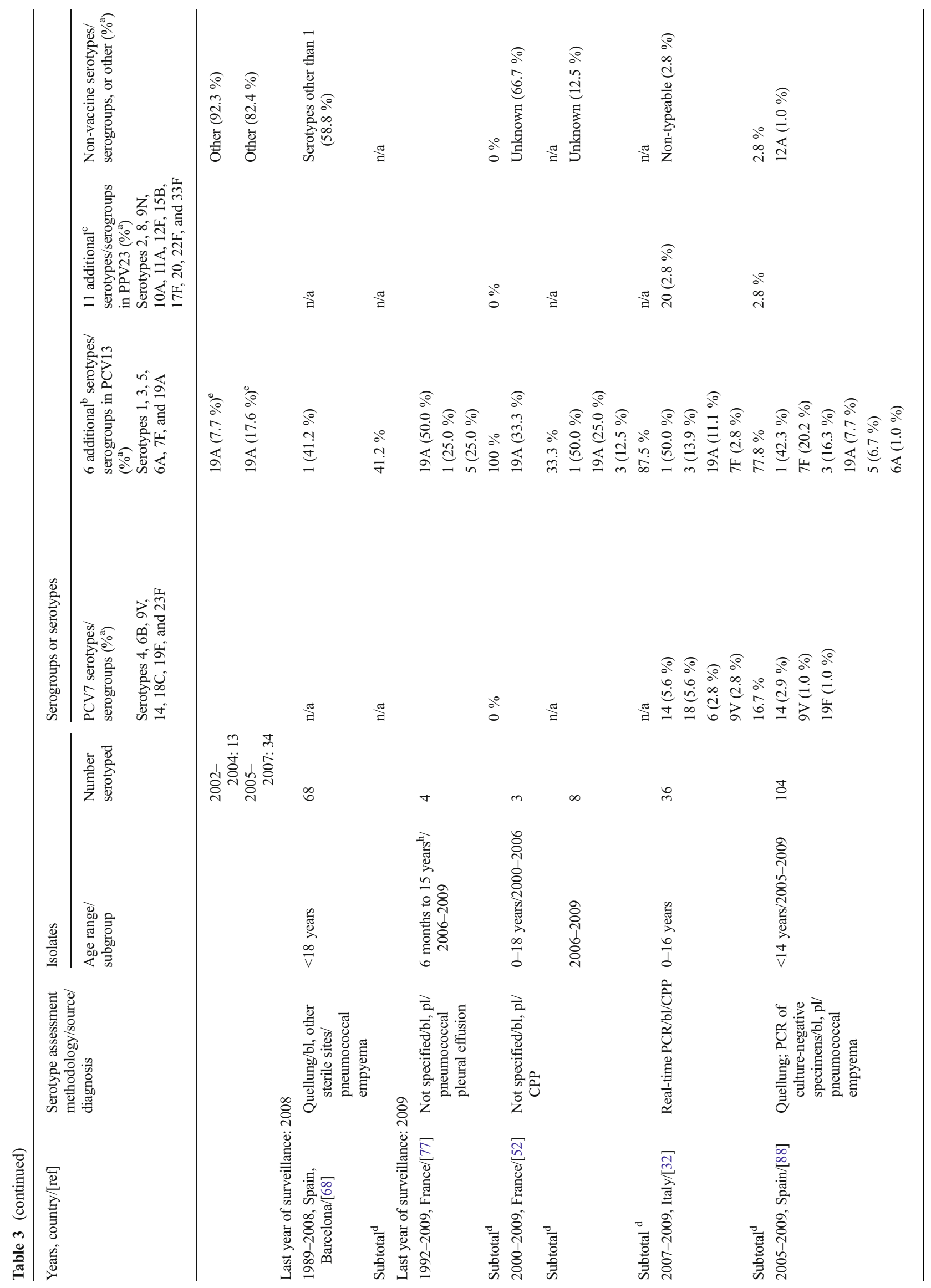




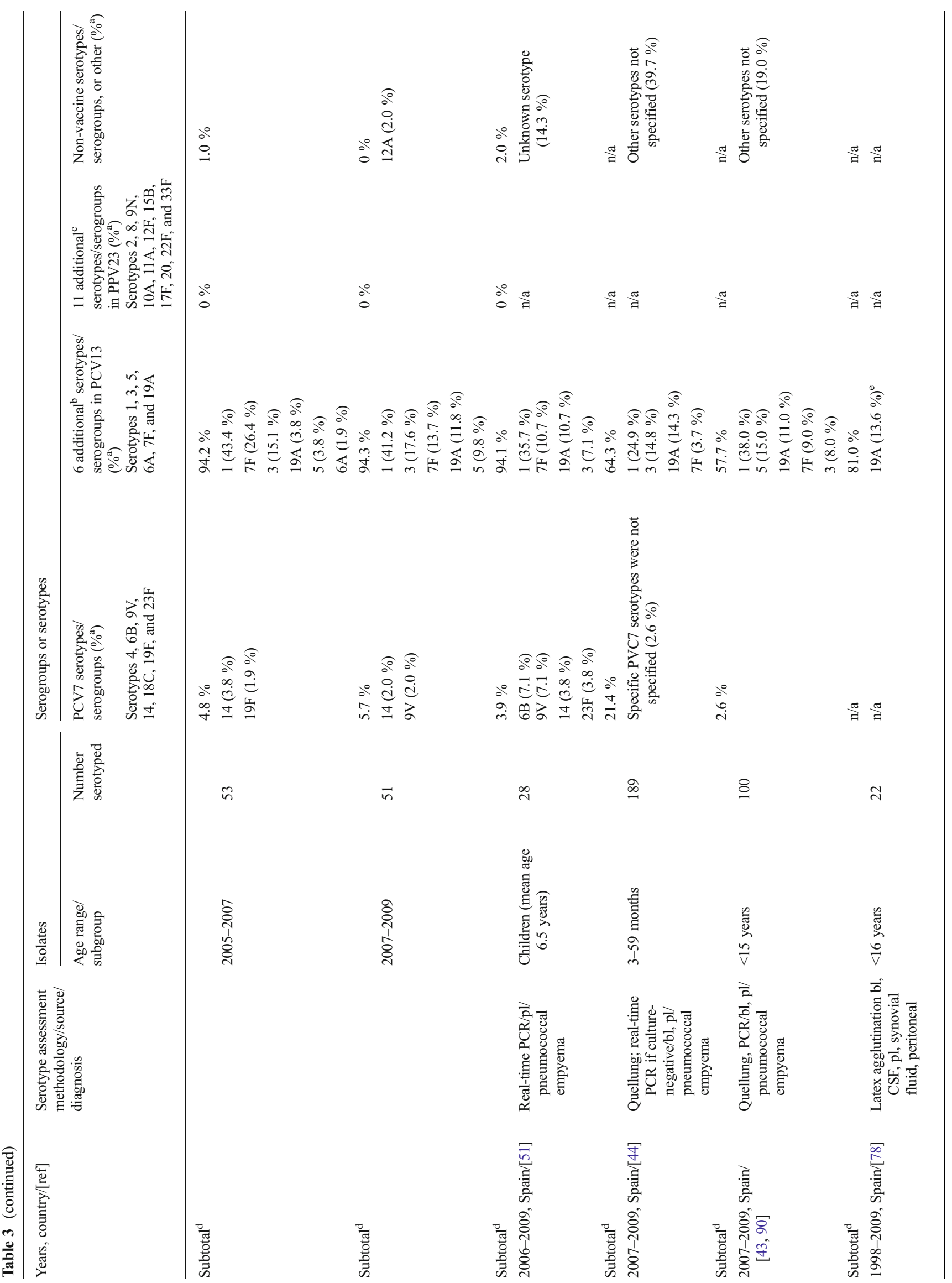




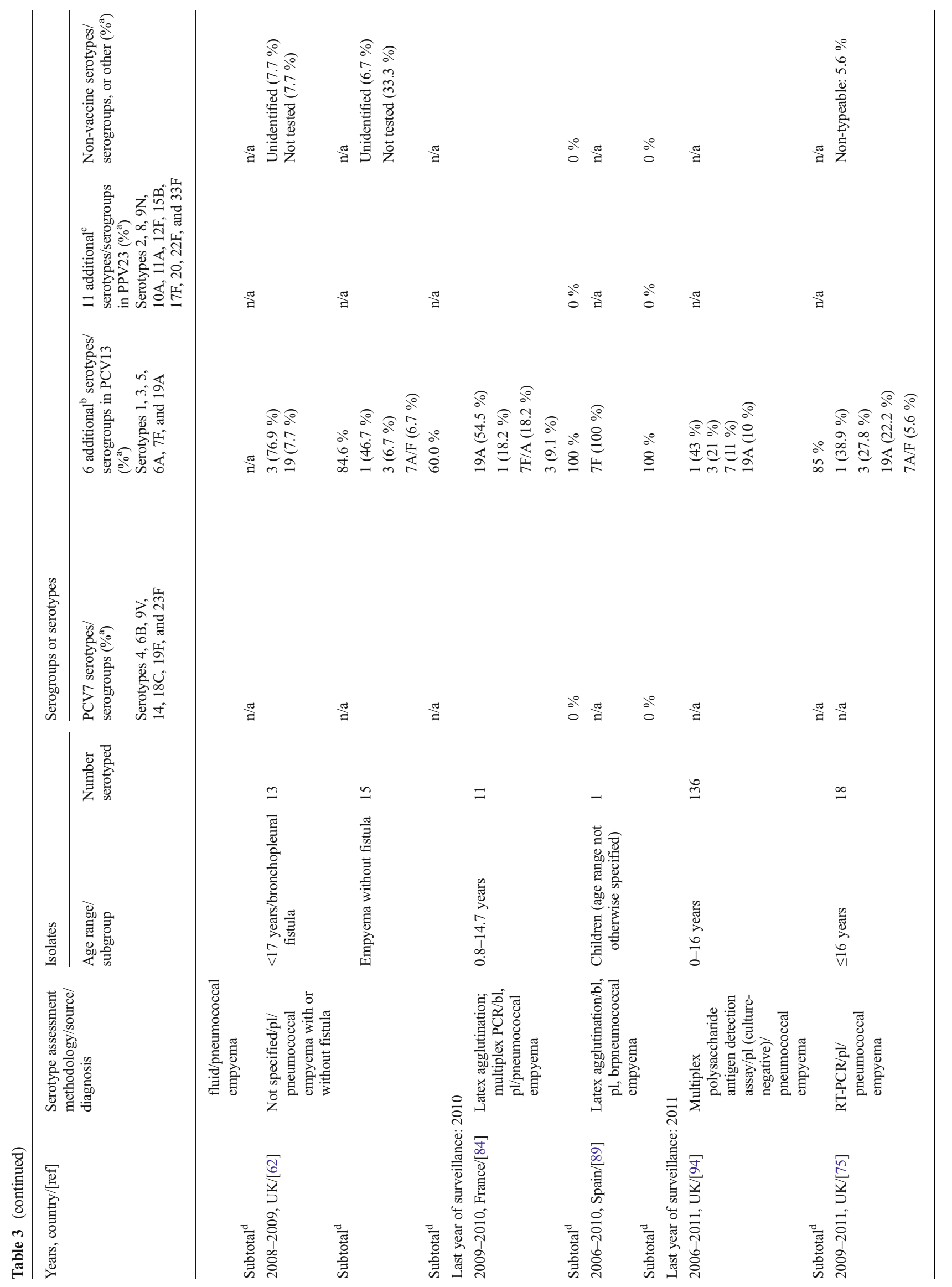




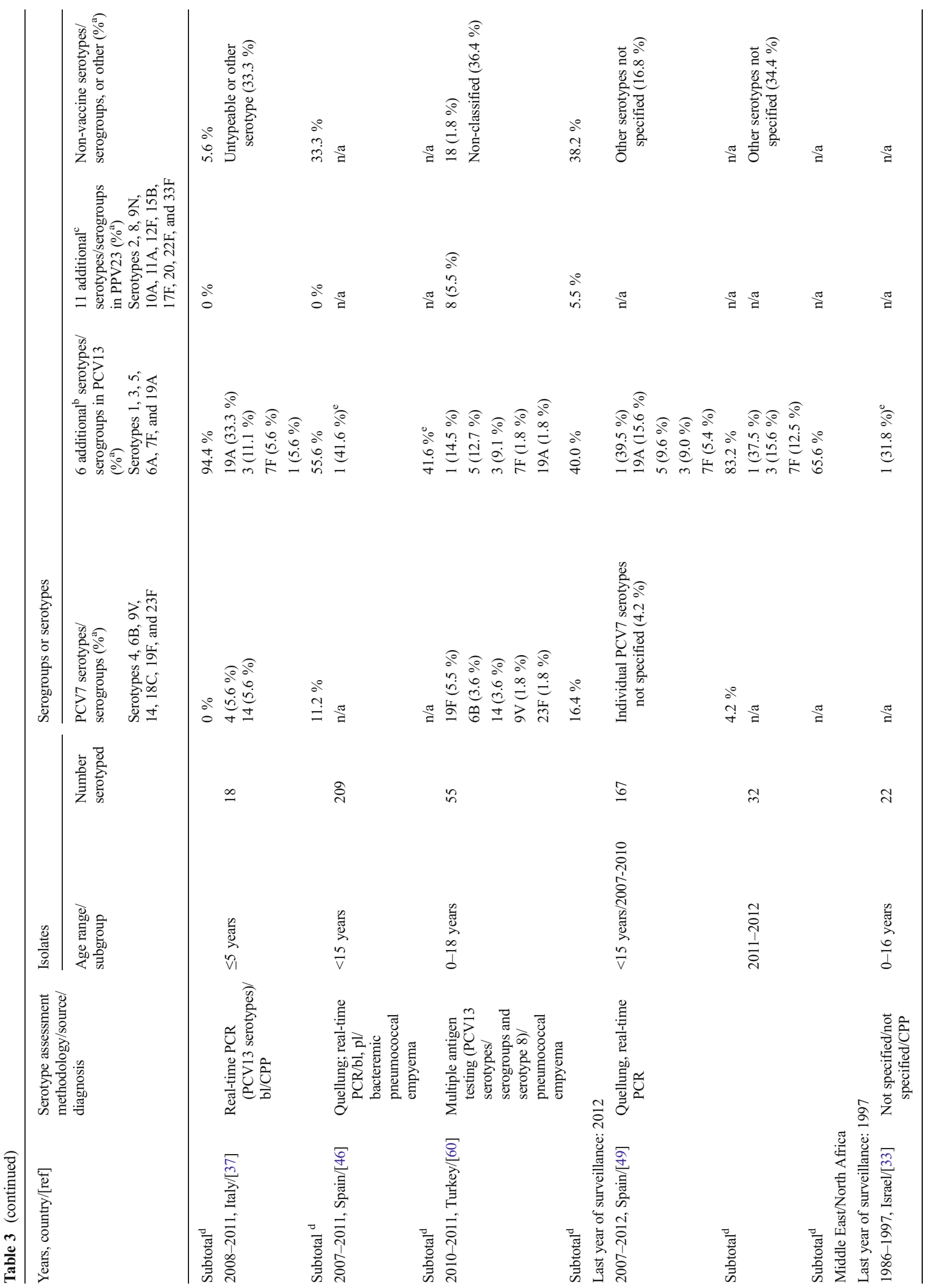




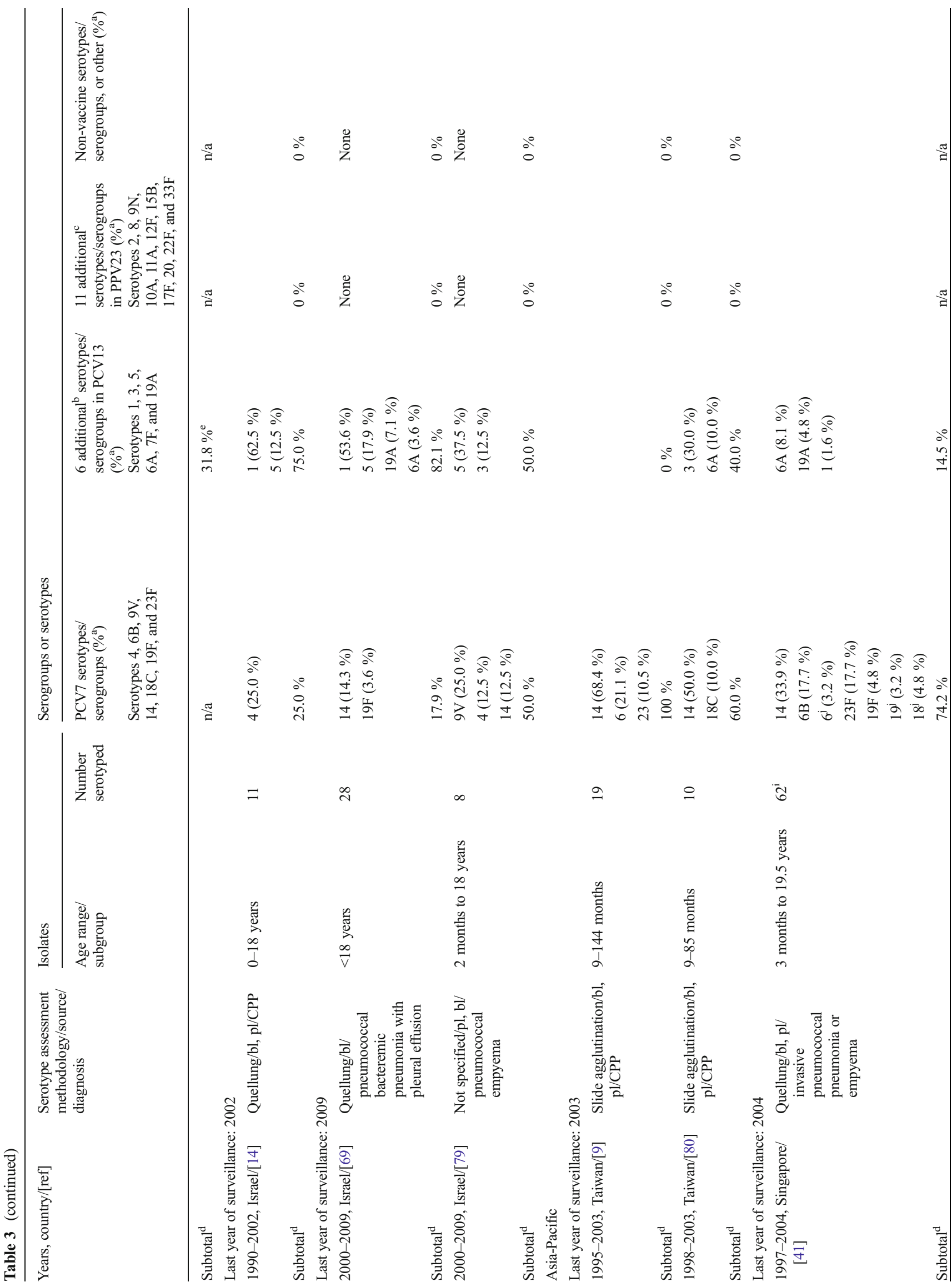




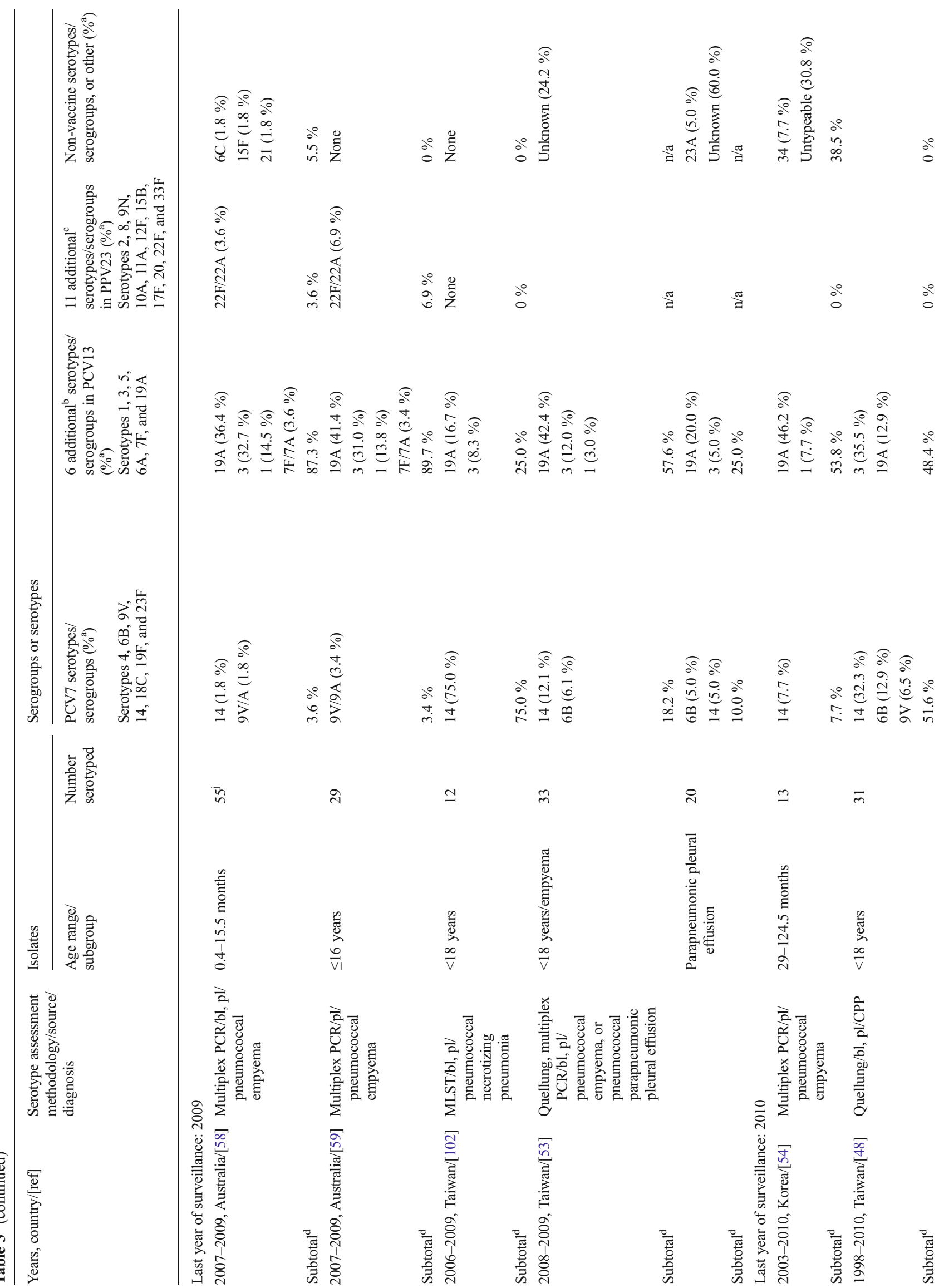




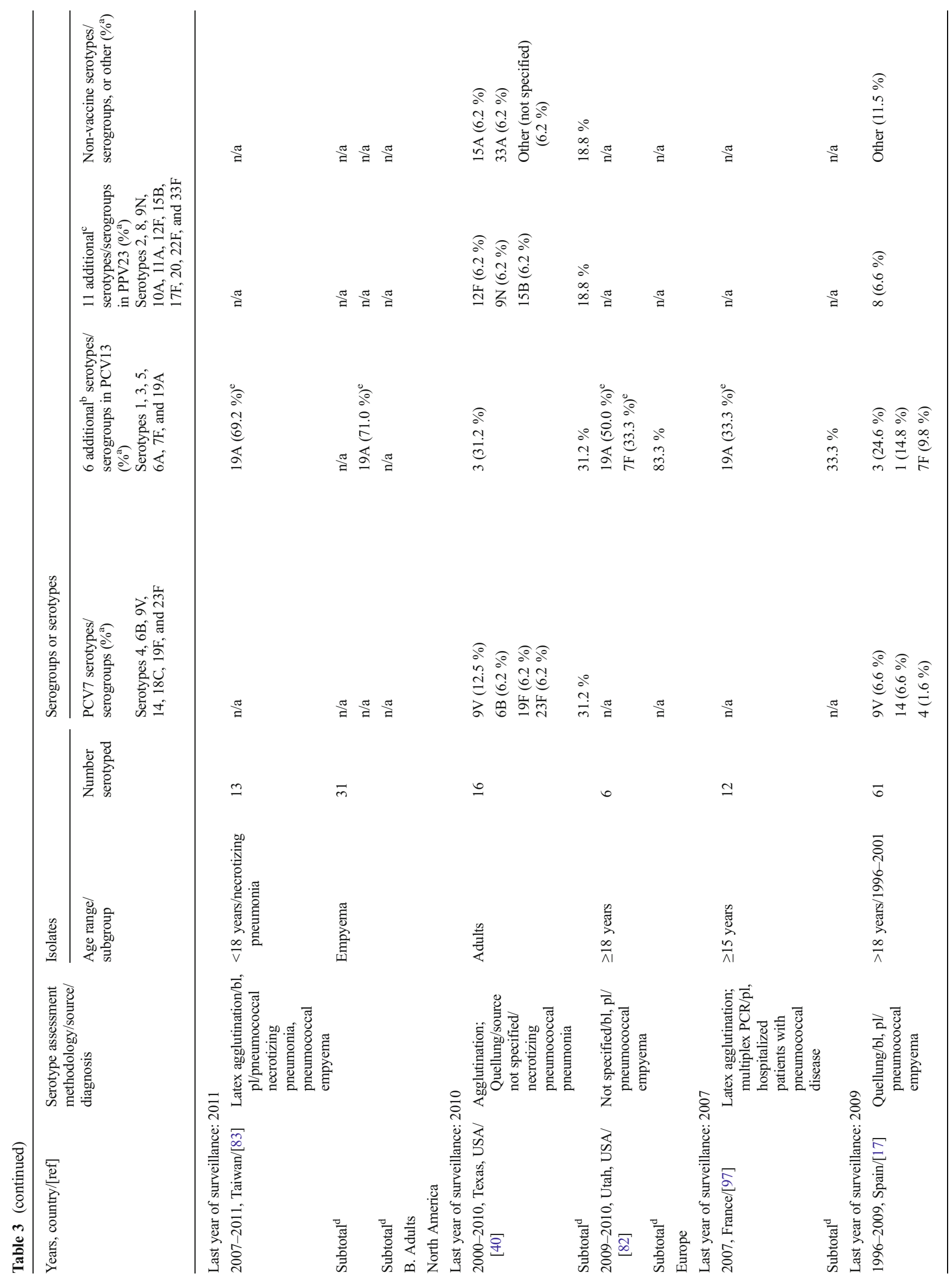




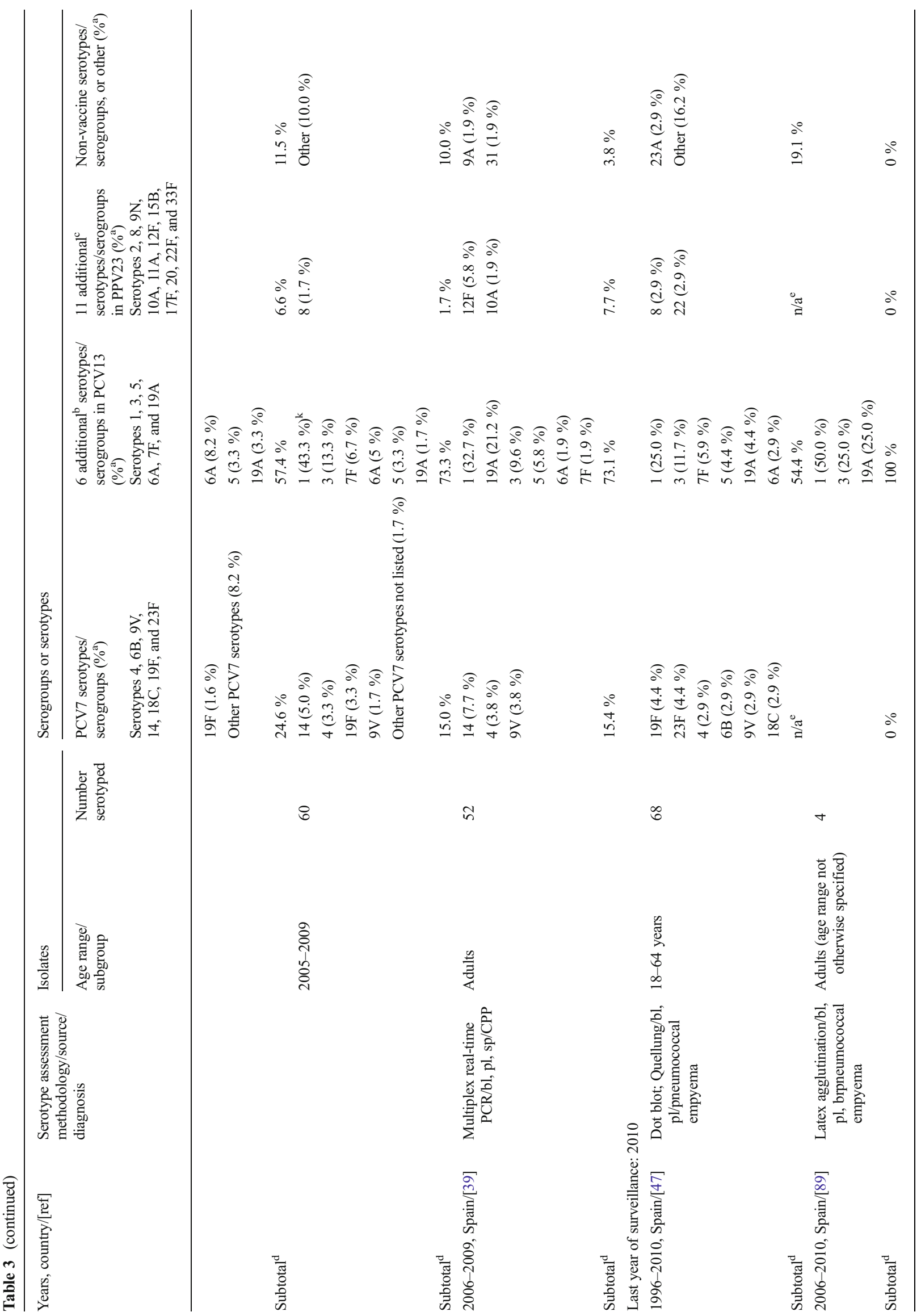




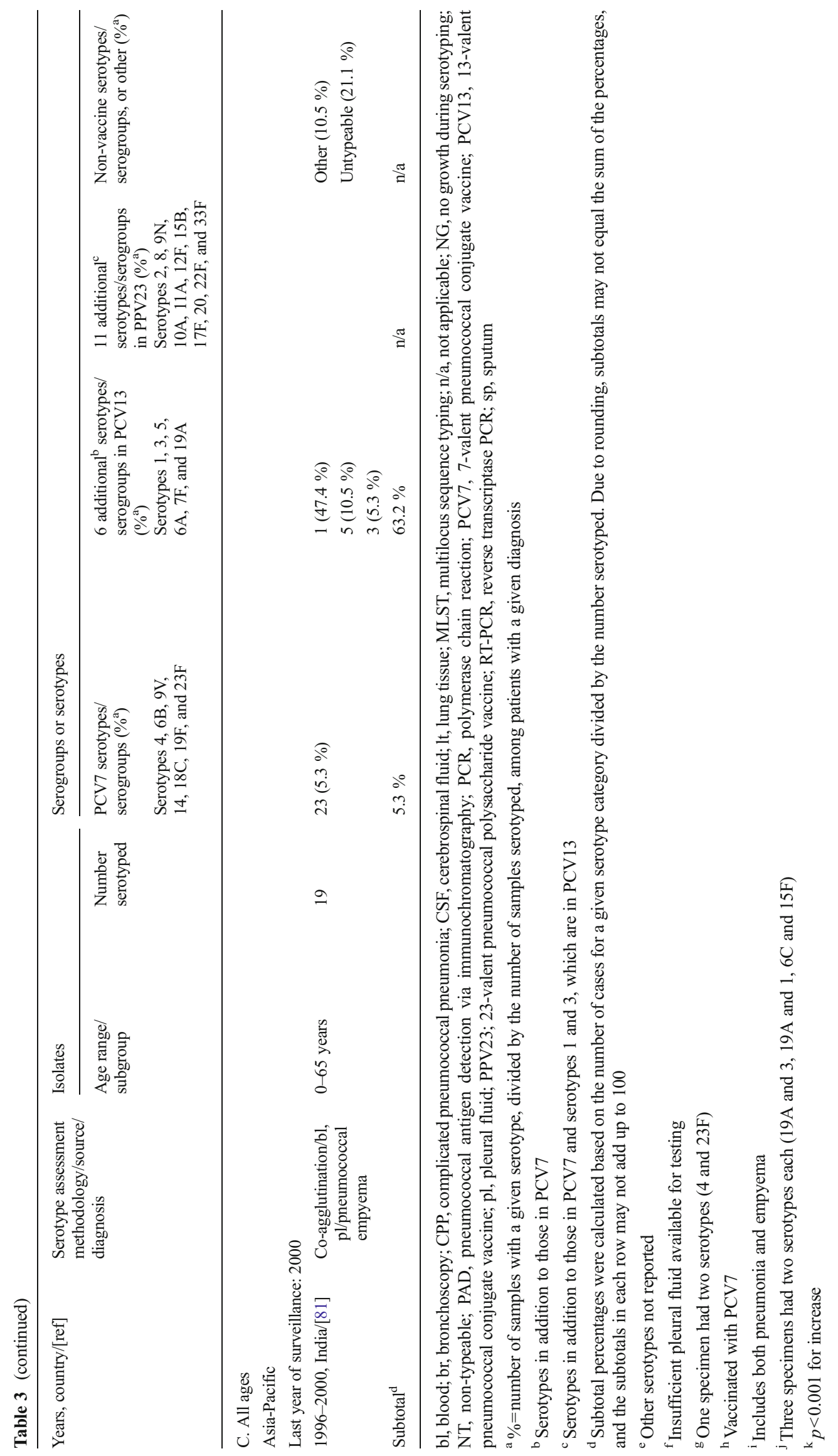


2006), serotype 3 was the most frequent cause of pneumococcal necrotizing pneumonia (28.9\%; 11/38 cases), whereas serotype 1 (22.6\%; 28/124 cases) was predominant in uncomplicated pneumococcal pneumonia [35]. Conversely, among children with community-acquired invasive pneumococcal pneumonia (IPP) (i.e., pneumonia with S. pneumoniae isolated from blood or pleural fluid) in Italy (2007-2009), serotype 1 caused a significantly higher percentage of CPP than uncomplicated pneumonia (50 \% vs. $18.2 \% ; p=0.005$ ) [32]. In children aged $<18$ years in Taiwan (1998-2010), the proportions of cases of CPP caused by PCV7 and non-PCV7 serotypes were similar ( $51.6 \%$ and $48.4 \%$, respectively), and serotypes 14 and 3 were the most common serotypes (32.3\% and $35.5 \%$ of cases, respectively). Serotype 3 was the most common serotype causing CPP compared with uncomplicated lobar pneumonia (OR, 0.114; $95 \%$ confidence interval [CI], $0.013-0.973)$ [48].

In children with any-cause empyema in the UK (20022009), S. pneumoniae was the most frequently isolated organism, found in 44 of 70 children (62.9\%) from whom an organism was identified [62]. Serotype 3 was significantly more common in pneumococcal bronchopleural fistula (10/ 13 cases) compared with no fistula $(1 / 15$ cases $)(p<0.0001)$, whereas serotype 1 was the most common serotype among cases without fistula (7/15 cases) and was not found among those with fistula [62]. In children in England with cavitatory disease complicating PnEmp or pneumococcal parapneumonic effusion, the most common serotypes were 1 (4/11 cases, $36.4 \%$ ) and 3 (3/11 cases, $27.3 \%$ ) [55].

Among Spanish adults (2006-2009), serotype 1 was the most frequent cause of CPP (32.7\%) and uncomplicated pneumococcal pneumonia (31.2\%); the other frequent causes of complicated pneumonia, in descending order of frequency, were serotypes 19A, 3, 14, 5, and 12F (Table 3) [39]. In adults in the USA with pneumococcal pneumonia $(n=351)$, serotype 3 , the most common cause of pneumonia overall, was isolated in 5 of 16 specimens ( $31.2 \%$ ) from patients with pneumococcal necrosis; 10 other serotypes caused the remaining 11 cases (Table 3) [40].

Serotype 1 undergoes periodic outbreaks, so it is possible that increases in serotype 1 PnEmp may be associated with a cyclic pattern [87]. Serotype 1 clones were analyzed in PnEmp among children [31, 87, 101] and adults [47]. Multilocus sequence typing (MLST) analysis of pediatric PnEmp cases in Utah (USA) suggested that replacement sequence types (STs) contributed to the increase in incidence of pediatric PnEmp post-PCV7 [31]. Before 2001, only ST227 (serotype 1) was identified; by 2003, six additional STs were associated with serotype 1, including a single-locus variant of ST227. In contrast, among serotype 1 isolates causing pediatric PnEmp in Spain (2004-2006), three clones were identified (ST228, ST306, and ST304); these were historically wellestablished clones [101]. A more recent study of pediatric
PnEmp in Spain (2003-2006) identified the same three serotype 1 clones in pleural fluid [87]. MLST types associated with the increased incidence of pediatric PnEmp had been present previously in Spain and elsewhere in Europe, and, therefore, the increase in proportions of PnEmp (predominantly serotype 1) was probably not associated with the emergence of new clones or of capsular switching [87, 101]. For adults in Spain (1996-2010), an increase in PnEmp incidence in otherwise healthy adults with pneumonia was associated predominantly with serotype 1, in particular, ST306 [47].

Antibiotic resistance

Antibiotic sensitivity data are available from CPP isolates, which are predominately the serotypes 14, 1, and 19A; among these three predominant PCV13 serotypes, only 19A tends to be associated with antibiotic resistance (probably due to its relationship with nasopharyngeal carriage).

Among children in Utah (USA) (1993-1999), PnEmp was less likely than uncomplicated pneumococcal pneumonia to be caused by penicillin-resistant pneumococci $(16 \%$ vs. $48 \%$; $p=0.0021)$; all serotype 1 isolates were penicillin-susceptible [30]. For pediatric CPP in Tennessee (USA) (1996-2001), all serotype 1 isolates $(n=5)$ were susceptible to penicillin, whereas 5 of 7 serotype 14 isolates (the most frequently identified isolate in this sample) were penicillin-resistant [7]. (By contrast, in eight children's hospitals in the USA (19932000), the antibiotic resistance rates were similar among isolates from CPP and uncomplicated pneumococcal pneumonias [34].)

Serotype $19 \mathrm{~A}$ is associated with reduced sensitivity to antibiotics $[15,53,83,90]$. In Spain, $11 \%$ of cases of pediatric PnEmp were caused by serotype 19A; all three culturepositive serotype 19A isolates were non-susceptible to cefotaxime, and two were also non-susceptible to parenteral penicillin [90]. Other serotypes isolated in this study $(1,5$, and 7F) were susceptible to parenteral beta-lactams and showed low rates of resistance to oral penicillin and erythromycin. In another Spanish study (2003-2006), 8 of 27 pneumococcal isolates from pediatric PnEmp showed reduced susceptibility to penicillin; two serotype 19A isolates and one each of serotypes 14 and 3 showed resistance to multiple antibiotics [15]. Similarly, in Taiwan (2007-2011), serotype 19A isolates from pediatric PnEmp had lower levels of susceptibility to cefotaxime than non-19A isolates, although the 19A and non19A isolates had similar susceptibility to other antibiotics [83]. In Taiwanese children with empyema (2008-2009), 4 of 8 pneumococcal isolates were penicillin-resistant (i.e., serotypes 19A [ $n=3]$ and $14[n=1])$ [53].

Several studies evaluated the association of pneumococcal conjugate vaccine introduction with antibiotic resistance among pneumococcal serotypes associated with CPP or PnEmp. In Israel (1990-2002), no penicillin-resistant pneumococci were 
isolated from pediatric CPP [14], whereas in Taiwan (19952003), more pneumococcal isolates from pediatric CPP than from lobar pneumonia were intermediately susceptible or resistant to penicillin [9]. In a subsequent study (1996-2005), the penicillin resistance rates in PnEmp declined from $21 \%$ to $12 \%$ $(p=0.3)$ following PCV7 introduction [73]. Similarly, in Spain (2005-2009), all pneumococcal isolates $(n=34)$ from pediatric PnEmp were susceptible to penicillin [88].

In Spanish adults (2001-2009), significantly higher proportions of penicillin-susceptible isolates $(p=0.013)$ were identified from CPP compared with uncomplicated pneumococcal pneumonia, which was associated with a higher rate of erythromycin resistance $(p=0.033)$ [74]. Among adults in Spain with IPP, antibiotic resistance decreased and antibiotic susceptibility increased between 1996-2001 and 2005-2009, significantly so for penicillin $(p=0.01)$ [63]. Likewise, among adults with IPP in Spain (1996-2009), the proportion of cases caused by penicillin-susceptible pneumococcal strains increased from $71.7 \%$ to $80.3 \%$ ( $p=0.012$ ), and susceptibility to other antibiotics also trended upward [17].

\section{Effect of age on serotype epidemiology}

Age-based differences were observed in pneumococcal serotype proportions. In France (2007), both serotypes 1 (5/10 isolates) and 19A (5/10 isolates) were uniquely isolated from pleural fluid in children with IPD, whereas from pleural fluid in adults, the most frequent was serotype 19A (4/12 isolates) [97]. In Spanish studies, serotype 1 was associated with IPD in older children, whereas serotype 19A predominated in younger children [44, 49, 87, 90]. In Spain (2007-2009), among children aged 3-59 months with IPD, serotype 1 was the most frequent cause of PnEmp ( $24.9 \%$ of all cases), and serotype 1 IPD was significantly more common in children aged 24 59 months than those aged 3-23 months (adjusted OR, 7.70; $95 \%$ CI, 2.12-10.38) [44]. Serotype 19A-related IPD was noted to be more common among children aged $<24$ months, although the proportion of cases with PnEmp in this age group was not specified, and serotype 19A was also associated with PnEmp (14.3\% of all cases). In another Spanish study (20032006), serotypes 1, 5, 7F, and 14 (i.e., serotypes with higher invasive disease potential) were more frequent causes of PnEmp in older children (median ages 56 months vs. 24 months; $p=0.0001$ ) compared with serotypes $6 \mathrm{~A}, 9 \mathrm{~V}, 19 \mathrm{~A}$, and $23 \mathrm{~F}$ (i.e., serotypes with low invasive disease potential) [87]. This pattern was also evident in pediatric pneumonia in Italy (2007-2009): serotype 1 was only detected in children aged $>2$ years and was the predominant serotype associated with CPP (50\% of cases), whereas serotype 19A was significantly associated with younger age [32]. In Spanish children with PnEmp (2007-2009), serotype 1 was more common in children aged $>36$ months, serotype 3 was more common in children aged 24-36-months, and serotype 19A was more common in children aged $<24$ months [90]. More recently, in a Spanish study of children aged $<15$ years with PnEmp (2007-2012), the median overall age (52.0 vs. 44.0 months; $p=0.028)$ and the age of children with serotype 1 disease (74.0 vs. 49.5 months; $p=0.002$ ) was significantly higher one year after the introduction of PCV13 (2011-2012) compared with 2007-2010 [49].

\section{Discussion}

The reported proportion of cases of CPP and PnEmp has increased over the past several decades. For example, among children aged $<18$ years with IPD in Utah (USA), the most common form of IPD had been bacteremia without focus (37\%) during 1997-2000, whereas by 2001-2010, CPP became the most common form of IPD (33\%); the proportion of CPP increased from $17 \%(22 / 128$ cases) to $33 \%$ (127/385 cases) $(p<0.001)$ [18]. Among hospitalized children with IPD in Barcelona (Spain), the mean number of cases of PnEmp increased significantly from 1998-2001 to 2002-2005 (15 vs. 43, respectively; $p<0.02$ ) [101].

Serotypes 1, 19A, 3, 14, and 7F predominated as causes of CPP and empyema. For example, in the USA (1993-2000), the most frequent serotypes causing pediatric CPP were serotypes $14(29.1 \%)$ and $1(24.4 \%)$ [34]. In another study in the USA (1996-2001), serotypes 14 (35.0 \%), 1 (25.0\%), and 19A (15.0\%) were the most frequent causes of CPP [7]. In a study in Italy among children with CPP $(n=35)$, serotypes 1 $(50.0 \%), 3(13.9 \%)$, and 19A (11.1\%) predominated [32].

After the introduction of PCV7 into pediatric immunization programs, several studies reported increases in the proportion of CPP caused by non-PCV7 serotypes, particularly serotypes 1, 3, 7F, and 19A [17, 18, 31, 35, 50, 52]. In Barcelona (Spain), the proportion of serotype 19A pediatric PE increased from none $(0 / 7)$ in $1997-2001$, to $1 / 13$ cases ( $8 \%$ ) during 2002-2004, to 6/34 cases (18\%) during 2005-2007; these data also reflect an increase in the overall number of pediatric PnEmp cases [86]. PCV7 serotypes and non-PCV7 serotypes caused similar proportions of cases of CPP $(51.6 \%$ and $48.4 \%$, respectively) in children in Taiwan during a period (1998-2010) when PCV7 immunization rates were low (i.e., in $2007,15.9 \%$ of children aged $<5$ years had received $\geq 1$ dose), although serotype 3 was significantly more likely to cause CPP compared with lobar pneumonia [48]. While fewer data are available for PnEmp in adults, a Spanish study reported significant increases from 1996-2001 to 20052009 in the PnEmp incidence ( 0.5 to 1.6 cases/100,000 population; $p<0.001$ ) and the serotype 1 PnEmp incidence ( 0.1 to 0.8 cases per 100,000 population; $p<0.001)$ in adults aged 18-50 years [17]. In England, the serotype 19A incidence for pediatric CPP increased significantly from 0.48 to 2.02 per 
1,000,000 children from 2006-2007 to 2010-2011 (incidence rate ratio, 4.17; $95 \%$ CI, 1.53-14.2) [94].

Although in some studies the emergence of serotypes 1, 19A, 3, and 14 in CPP and PnEmp has corresponded to the years following the introduction of PCV7 [17, 18, 31, 35, 50, $52,86]$, a few studies demonstrated that their increasing role in CPP and PnEmp began prior to the introduction of PCV7 [28, 29, 68]. For example, in a study of IPD in Spain (1989-2008), the proportion of cases of IPD caused by serotype 1 was increasing prior to the introduction of PCV7, and this trend continued after the introduction of PCV7 ( $2 \%, 8.6 \%, 14.9 \%$, and $23.8 \%$ of cases in 1989-1993, 1994-1998, 1993-2003, and 2004-2008, respectively [ $p<0.001]$ ] [68]. This suggests that emergence involves more than simply serotype replacement following PCV7 introduction; characteristics particular to certain serotypes, such as differences in antibiotic sensitivity or their propensity to cause pleural infection, may be responsible for these increases. In addition, several studies established a relationship between the proportion of CPP and age that contrasts with the age-specific incidence of IPD [32, 40, 44, 49, 87, $90,97]$, which may suggest an interaction between the propensity of given serotypes to infect and the age-dependent susceptibility of patients to infection by these same serotypes.

Recent data suggest that PCV13 may impact on pediatric PnEmp caused by serotypes associated with CPP, such as 1 and 19A. In Spain, where PCV13 was introduced in 2010, the incidence of pediatric PnEmp caused by serotypes targeted by PCV13 declined significantly from 2009-2010 to 2010-2011 (5.52 vs. 3.55 per 100,000 population; $p=0.049$ ), mainly due to reductions in serotypes 1 ( 2.81 vs. 2.07 per 100,000 population) and $19 \mathrm{~A}$ (1.51 vs. 0.69 per 100,000 population) [46]. More recently, in children aged $<15$ years in Spain, the PnEmp incidence declined significantly $(p=0.0019)$ from 5.72 to. 3.12 per 100,000 population in, respectively, 2007-2010 and 2011-2012, while the median age of children with PnEmp was greater in 2011-2012 (i.e., following PCV13 introduction) than 2007-2010 (47.0 vs. 42.0 months; $p=0.032$ ) [49].

Although this review has recapitulated the basic epidemiology of CPP (including PnEmp) over the past several decades, the increased use of more specific diagnostic imaging (e.g., CT and ultrasound) in recent years may affect the reported rate of $\mathrm{PE}$ and empyema because of the more accurate identification. Improved diagnostic methodologies, clinical (ultrasound or CT vs. physical examination or chest X-ray) and microbiological (e.g., PCR vs. culture), as well as increased awareness of and vigilance for PE and empyema may have resulted in an apparent increase in the proportion of CPP over the time period included in this analysis, which, given the limitations of the retrospective nature of this analysis, may be a confounding factor in the determination of any true increase in the proportion of CPP.

This review is also limited by the fact that many of the studies used culture to identify pathogens. Culture may be less than ideally sensitive to the presence of specific pathogens because of factors such as prior antibiotic use or other difficulties in culturing pathogens. In recent years, PCR has been applied to identify the pneumococci causing CPP and to identify serotypes in culture-negative specimens $[32,59,64$, $84,87,93]$. As antibiotic treatment may reduce the likelihood of detecting bacteria via culture, PCR is useful in detecting pneumococci in culture-negative samples from patients previously treated with antibiotics. For example, in a Spanish study of culture-negative pleural fluid specimens from children with empyema, PCR typing identified eight different serotypes (i.e., serotypes 1, 3, 5, 7F/7A, 8, 14, 19A, and 19F/B/C) in 52 of 67 culture-negative pleural fluid samples from children with PnEmp, with a sensitivity of $96.0 \%$ and a specificity of $98.6 \%$ [93]. Spanish pediatric empyema patients with S. pneumoniae culture-negative/PCR-positive samples were found to be significantly more likely to have received antibiotics than those with culture-positive samples ( $92 \%$ vs. $53 \%$, respectively; $p<0.0001$ ) [87]. Rapid pneumococcal antigen detection by means of immunochromatography has also been used to detect pneumococci in isolates from patients with empyema [51]. In hospitalized children with parapneumonic effusion, conventional microbiologic culture of pleural fluid samples detected pneumococci in 15 of 55 isolates, real-time PCR detected pneumococci in 13 of 16 culture-negative isolates $(81.2 \%)$, and immunochromatographic testing detected pneumococci in 24 of 27 culture-negative isolates (88.9\%) [51]. Such molecular methods may complete the information available on changes in the IPD and CPP serotype epidemiology over time.

Finally, most of the studies reviewed here used retrospective database analyses to identify cases of CPP and PnEmp. The specificity of information in these databases could vary, as cases may have been missed due to misclassification. In recent years, increased awareness of CPP and PnEmp has led to prospective surveillance studies, which may enhance disease identification. In addition, studies used different breakpoints to determine penicillin sensitivity, making it difficult to compare antibiotic resistance results.

In conclusion, the reported proportion of cases of $\mathrm{CPP}$ and PnEmp due to non-PCV7 serotypes has increased over the past several decades in countries that introduced PCV7 into the pediatric immunization program. Whether this increase reflects the advent and wider use of more specific diagnostic methods and increased awareness due to research initiatives, or if it, indeed, represents a true increase in disease incidence, is unclear. Several factors may account for these greater proportions, including enhanced disease detection due to a higher index of suspicion and more sophisticated diagnostic assays, as well as the prevalence of certain non-PCV7 serotypes that are capable of invading the pleural space.

It is established that reductions in the proportion of PCV7 serotype CPP have been observed in countries using PCV7. 
Most serotypes associated with CPP and PnEmp-particularly serotypes 1, 19A, 3, and 7F-are targeted by PCV13, which was registered for pediatric vaccination from 2009 and for adult vaccination from 2011. Early reports suggest declines in the incidence and proportion of cases of vaccine serotype CPP post-PCV7 introduction, and then further with PCV13, although studies are ongoing.

Acknowledgments Medical writing support was provided by Vicki Schwartz, PhD, of Excerpta Medica and was funded by Pfizer Inc.

Conflict of interest The authors are employees of Pfizer Inc.

\section{References}

1. World Health Organization (WHO) (2008) 23-valent pneumococcal polysaccharide vaccine. WHO position paper. Wkly Epidemiol Rec 83:373-384

2. World Health Organization (WHO) (2009) Acute respiratory infections (update February 2009). Available online at: http://apps.who. int/vaccine_research/diseases/ari/en/. Accessed 22 November 2013

3. Sahn SA (2007) Diagnosis and management of parapneumonic effusions and empyema. Clin Infect Dis 45:1480-1486

4. Spencer DA, Cliff D (2008) The changing epidemiology of parapneumonic empyema in children. Paediatr Child Health 18: 513-518

5. Balfour-Lynn IM, Abrahamson E, Cohen G, Hartley J, King S, Parikh D et al; Paediatric Pleural Diseases Subcommittee of the BTS Standards of Care Committee (2005) BTS guidelines for the management of pleural infection in children. Thorax 60:i1-i21

6. Lisboa T, Waterer GW, Lee YCG (2011) Pleural infection: changing bacteriology and its implications. Respirology 16:598-603

7. Buckingham SC, King MD, Miller ML (2003) Incidence and etiologies of complicated parapneumonic effusions in children, 1996 to 2001. Pediatr Infect Dis J 22:499-504

8. Eastham KM, Freeman R, Kearns AM, Eltringham G, Clark J, Leeming J et al (2004) Clinical features, aetiology and outcome of empyema in children in the north east of England. Thorax 59:522 525

9. Hsieh YC, Hsueh PR, Lu CY, Lee PI, Lee CY, Huang LM (2004) Clinical manifestations and molecular epidemiology of necrotizing pneumonia and empyema caused by Streptococcus pneumoniae in children in Taiwan. Clin Infect Dis 38:830-835

10. Byington CL, Samore MH, Stoddard GJ, Barlow S, Daly J, Korgenski K et al (2005) Temporal trends of invasive disease due to Streptococcus pneumoniae among children in the intermountain west: emergence of nonvaccine serogroups. Clin Infect Dis 41:2129

11. Lin CJ, Chen PY, Huang FL, Lee T, Chi CS, Lin CY (2006) Radiographic, clinical, and prognostic features of complicated and uncomplicated community-acquired lobar pneumonia in children. J Microbiol Immunol Infect 39:489-495

12. Muñoz-Almagro C, Jordan I, Gene A, Latorre C, Garcia-Garcia JJ, Pallares R (2008) Emergence of invasive pneumococcal disease caused by nonvaccine serotypes in the era of 7 -valent conjugate vaccine. Clin Infect Dis 46:174-182

13. Nyambat B, Kilgore PE, Yong DE, Anh DD, Chiu CH, Shen X et al (2008) Survey of childhood empyema in Asia: implications for detecting the unmeasured burden of culture-negative bacterial disease. BMC Infect Dis 8:90
14. Goldbart AD, Leibovitz E, Porat N, Givon-Lavi N, Drukmann I, Tal A et al (2009) Complicated community acquired pneumonia in children prior to the introduction of the pneumococcal conjugated vaccine. Scand J Infect Dis 41:182-187

15. Hernández-Bou S, García-García JJ, Esteva C, Gené A, Luaces C, Muñoz Almagro C (2009) Pediatric parapneumonic pleural effusion: epidemiology, clinical characteristics, and microbiological diagnosis. Pediatr Pulmol 44:1192-1200

16. Grijalva CG, Nuorti JP, Zhu Y, Griffin MR (2010) Increasing incidence of empyema complicating childhood community-acquired pneumonia in the United States. Clin Infect Dis 50:805-813

17. Burgos J, Lujan M, Falcó V, Sánchez A, Puig M, Borrego A et al (2011) The spectrum of pneumococcal empyema in adults in the early 21 st century. Clin Infect Dis 53:254-261

18. Ampofo K, Pavia AT, Chris S, Hersh AL, Bender JM, Blaschke AJ et al (2012) The changing epidemiology of invasive pneumococcal disease at a tertiary children's hospital through the 7-valent pneumococcal conjugate vaccine era: a case for continuous surveillance. Pediatr Infect Dis J 31:228-234

19. Strachan RE, Snelling TL, Jaffé A (2013) Increased paediatric hospitalizations for empyema in Australia after introduction of the 7-valent pneumococcal conjugate vaccine. Bull World Health Organ 91:167-173

20. Huss A, Scott P, Stuck AE, Trotter C, Egger M (2009) Efficacy of pneumococcal vaccination in adults: a meta-analysis. CMAJ 180: $48-58$

21. Moberley S, Holden J, Tatham DP, Andrews RM (2013) Vaccines for preventing pneumococcal infection in adults. Cochrane Database Syst Rev 1:CD000422

22. McIntosh ED, Reinert RR (2011) Global prevailing and emerging pneumococcal serotypes. Expert Rev Vaccines 10:109-129

23. Centers for Disease Control and Prevention (CDC) (2008) Invasive pneumococcal disease in children 5 years after conjugate vaccine introduction - eight states, 1998-2005. MMWR Morb Mortal Wkly Rep 57:144-148

24. Harboe ZB, Valentiner-Branth $P$, Ingels $H$, Rasmussen JN, Andersen PH, Bjerre CC et al (2013) Pediatric invasive pneumococcal disease caused by vaccine serotypes following the introduction of conjugate vaccination in Denmark. PLoS One 8:e51460

25. Pilishvili T, Lexau C, Farley MM, Hadler J, Harrison LH, Bennett NM et al (2010) Sustained reductions in invasive pneumococcal disease in the era of conjugate vaccine. J Infect Dis 201:32-41

26. Hanquet G, Kissling E, Fenoll A, George R, Lepoutre A, Lernout T et al (2010) Pneumococcal serotypes in children in 4 European countries. Emerg Infect Dis 16:1428-1439

27. Vestrheim DF, Høiby EA, Bergsaker MR, Rønning K, Aaberge IS, Caugant DA (2010) Indirect effect of conjugate pneumococcal vaccination in a 2+1 dose schedule. Vaccine 28:2214-2221

28. Fenoll A, Granizo JJ, Aguilar L, Giménez MJ, Aragoneses-Fenoll L, Hanquet G et al (2009) Temporal trends of invasive Streptococcus pneumoniae serotypes and antimicrobial resistance patterns in Spain from 1979 to 2007. J Clin Microbiol 47:1012-1020

29. Ihekweazu CA, Dance DA, Pebody R, George RC, Smith MD, Waight $P$ et al (2008) Trends in incidence of pneumococcal disease before introduction of conjugate vaccine: South West England, 1996-2005. Epidemiol Infect 136:1096-1102

30. Byington CL, Spencer LY, Johnson TA, Pavia AT, Allen D, Mason EO et al (2002) An epidemiological investigation of a sustained high rate of pediatric parapneumonic empyema: risk factors and microbiological associations. Clin Infect Dis 34:434-440

31. Byington CL, Hulten KG, Ampofo K, Sheng X, Pavia AT, Blaschke AJ et al (2010) Molecular epidemiology of pediatric pneumococcal empyema from 2001 to 2007 in Utah. J Clin Microbiol 48:520-525

32. Resti M, Moriondo M, Cortimiglia M, Indolfi G, Canessa C, Becciolini L et al (2010) Community-acquired bacteremic pneumococcal pneumonia in children: diagnosis and serotyping by real- 
time polymerase chain reaction using blood samples. Clin Infect Dis 51:1042-1049

33. Wexler ID, Knoll S, Picard E, Villa Y, Shoseyov D, Engelhard D et al (2006) Clinical characteristics and outcome of complicated pneumococcal pneumonia in a pediatric population. Pediatr Pulmonol 41:726-734

34. Tan TQ, Mason EO Jr, Wald ER, Barson WJ, Schutze GE, Bradley JS et al (2002) Clinical characteristics of children with complicated pneumonia caused by Streptococcus pneumoniae. Pediatrics 110:16

35. Bender JM, Ampofo K, Korgenski K, Daly J, Pavia AT, Mason EO et al (2008) Pneumococcal necrotizing pneumonia in Utah: does serotype matter? Clin Infect Dis 46:1346-1352

36. Yoshioka CR, Martinez MB, Brandileone MC, Ragazzi SB, Guerra ML, Santos SR et al (2011) Analysis of invasive pneumoniacausing strains of Streptococcus pneumoniae: serotypes and antimicrobial susceptibility. J Pediatria (Rio J) 87:70-75

37. Esposito S, Marchese A, Tozzi AE, Rossi GA, Da Dalt L, Bona G et al (2012) Bacteremic pneumococcal community-acquired pneumonia in children less than 5 years of age in Italy. Pediatr Infect Dis J 31:705-710

38. Vallès X, Marcos A, Pinart M, Piñer R, Marco F, Mensa JM et al (2006) Hospitalized community-acquired pneumonia due to Streptococcus pneumoniae: has resistance to antibiotics decreased? Chest 130:800-806

39. Cillóniz C, Ewig S, Polverino E, Muñoz-Almagro C, Marco F, Gabarrús A et al (2012) Pulmonary complications of pneumococcal community-acquired pneumonia: incidence, predictors, and outcomes. Clin Microbiol Infect 18:1134-1142

40. Pande A, Nasir S, Rueda AM, Matejowsky R, Ramos J, Doshi S et al (2012) The incidence of necrotizing changes in adults with pneumococcal pneumonia. Clin Infect Dis 54:10-16

41. Chong CY, Koh-Cheng T, Yee-Hui M, Nancy TW (2008) Invasive pneumococcal disease in Singapore children. Vaccine 26:3427-3431

42. Aguiar SI, Brito MJ, Gonçalo-Marques J, Melo-Cristino J, Ramirez M (2010) Serotypes 1, 7F and 19A became the leading causes of pediatric invasive pneumococcal infections in Portugal after 7 years of heptavalent conjugate vaccine use. Vaccine 28:5167-5173

43. Picazo J, Ruiz-Contreras J, Casado-Flores J, Giangaspro E, Del Castillo F, Hernández-Sampelayo T et al (2011) Relationship between serotypes, age, and clinical presentation of invasive pneumococcal disease in Madrid, Spain, after introduction of the 7-valent pneumococcal conjugate vaccine into the vaccination calendar. Clin Vaccine Immunol 18:89-94

44. Ciruela P, Soldevila N, Selva L, Hernández S, Garcia-Garcia JJ, Moraga F et al (2013) Are risk factors associated with invasive pneumococcal disease according to different serotypes? Hum Vaccin Immunother 9:712-719

45. Chacon-Cruz E, Velazco-Mendez Y, Navarro-Alvarez S, RivasLanderos RM, Volker ML, Lopez-Espinoza G (2012) Pneumococcal disease: emergence of serotypes 19A and 7F following conjugate pneumococcal vaccination in a Mexican hospital. J Infect Dev Ctries 6:516-520

46. Picazo J, Ruiz-Contreras J, Casado-Flores J, Giangaspro E, Garcíade-Miguel MJ, Hernández-Sampelayo T et al (2013) Impact of introduction of conjugate vaccines in the vaccination schedule on the incidence of pediatric invasive pneumococcal disease requiring hospitalization in Madrid 2007 to 2011. Pediatr Infect Dis J 32:656-661

47. Grau I, Ardanuy C, Calatayud L, Rolo D, Domenech A, Liñares J et al (2012) Invasive pneumococcal disease in healthy adults: increase of empyema associated with the clonal-type Sweden(1)ST306. PLoS One 7:e42595

48. Shen CF, Wang SM, Lee KH, Ho TS, Liu CC (2013) Childhood invasive pneumococcal disease caused by non-7-valent pneumococcal vaccine (PCV7) serotypes under partial immunization in Taiwan. J Formos Med Assoc 112:561-568
49. Picazo J, Ruiz-Contreras J, Casado-Flores J, Negreira S, García-deMiguel M-J, Hernández-Sampelayo T et al (2013) Expansion of serotype coverage in the universal pediatric vaccination calendar: short-term effects on age- and serotype-dependent incidence of invasive pneumococcal clinical presentations in Madrid, Spain. Clin Vaccine Immunol 20:1524-1530

50. Chibuk TK, Robinson JL, Hartfield DS (2010) Pediatric complicated pneumonia and pneumococcal serotype replacement: trends in hospitalized children pre and post introduction of routine vaccination with Pneumococcal Conjugate Vaccine (PCV7). Eur J Pediatr 169:1123-1128

51. Martinón-Torres F, Dosil-Gallardo S, Perez del Molino-Bernal ML, Sánchez FP, Tarrago D, Alvez F et al (2012) Pleural antigen assay in the diagnosis of pediatric pneumococcal empyema. J Crit Care 27: 321.e1-321.e4

52. Masson A, Ménetrey C, Garnier F, Bahans C, Fargeot A, Layadi M et al (2011) Parapneumonic pleural effusion incidence in a French region before and during the antipneumococcal vaccine era. Arch Pediatr 18:846-849

53. Lin TY, Hwang KP, Liu CC, Tang RB, Lin CY, Gilbert GL et al (2013) Etiology of empyema thoracis and parapneumonic pleural effusion in Taiwanese children and adolescents younger than 18 years of age. Pediatr Infect Dis J 32:419-421

54. Lee JH, Kim SH, Lee J, Choi EH, Lee HJ (2012) Diagnosis of pneumococcal empyema using immunochromatographic test on pleural fluid and serotype distribution in Korean children. Diagn Microbiol Infect Dis 72:119-124

55. Ramphul N, Eastham KM, Freeman R, Eltringham G, Kearns AM, Leeming JP et al (2006) Cavitatory lung disease complicating empyema in children. Pediatr Pulmonol 41:750-753

56. Langley JM, Kellner JD, Solomon N, Robinson JL, Le Saux N, McDonald J et al (2008) Empyema associated with communityacquired pneumonia: a Pediatric Investigator's Collaborative Network on Infections in Canada (PICNIC) study. BMC Infect Dis 8:129

57. Roxburgh CS, Youngson GG (2007) Childhood empyema in NorthEast Scotland over the past 15 years. Scott Med J 52:25-27

58. Strachan RE, Cornelius A, Gilbert GL, Gulliver T, Martin A, McDonald T et al (2011) Bacterial causes of empyema in children, Australia, 2007-2009. Emerg Infect Dis 17:1839-1845

59. Strachan RE, Cornelius A, Gilbert GL, Gulliver T, Martin A, McDonald $\mathrm{T}$ et al (2012) Pleural fluid nucleic acid testing enhances pneumococcal surveillance in children. Respirology 17:114-119

60. Ceyhan M, Ozsurekci Y, Gürler N, Ozkan S, Sensoy G, Belet N et al (2013) Distribution of Streptococcus pneumoniae serotypes that cause parapneumonic empyema in Turkey. Clin Vaccine Immunol 20:972-976

61. Grijalva CG, Zhu Y, Nuorti JP, Griffin MR (2011) Emergence of parapneumonic empyema in the USA. Thorax 66:663-668

62. McKee AJ, Ives A, Balfour-Lynn IM (2011) Increased incidence of bronchopulmonary fistulas complicating pediatric pneumonia. Pediatr Pulmonol 46:717-721

63. Burgos J, Falcó V, Borrego A, Sordé R, Larrosa MN, Martinez X et al (2013) Impact of the emergence of non-vaccine pneumococcal serotypes on the clinical presentation and outcome of adults with invasive pneumococcal pneumonia. Clin Microbiol Infect 19:385391

64. Blaschke AJ, Heyrend C, Byington CL, Obando I, Vazquez-Barba I, Doby EH et al (2011) Molecular analysis improves pathogen identification and epidemiologic study of pediatric parapneumonic empyema. Pediatr Infect Dis J 30:289-294

65. Eltringham G, Kearns A, Freeman R, Clark J, Spencer D, Eastham $\mathrm{K}$ et al (2003) Culture-negative childhood empyema is usually due to penicillin-sensitive Streptococcus pneumoniae capsular serotype 1. J Clin Microbiol 41:521-522 
66. Hortal M, Sehabiague G, Camou T, Iraola I, Estevan M, Pujadas M (2008) Pneumococcal pneumonia in hospitalized Uruguayan children and potential prevention with different vaccine formulations. $\mathrm{J}$ Pediatr 152:850-853

67. Yu J, Salamon D, Marcon M, Nahm MH (2011) Pneumococcal serotypes causing pneumonia with pleural effusion in pediatric patients. J Clin Microbiol 49:534-538

68. Esteva C, Selva L, de Sevilla MF, Garcia-Garcia JJ, Pallares R, Muñoz-Almagro C (2011) Streptococcus pneumoniae serotype 1 causing invasive disease among children in Barcelona over a 20 year period (1989-2008). Clin Microbiol Infect 17:1441-1444

69. Fuchs I, Dagan R, Givon-Lavi N, Greenberg D (2013) Serotype childhood invasive pneumococcal disease has unique characteristics compared to disease caused by other Streptococcus pneumoniae serotypes. Pediatr Infect Dis 32:614-618

70. Hendrickson DJ, Blumberg DA, Joad JP, Jhawar S, McDonald RJ (2008) Five-fold increase in pediatric parapneumonic empyema since introduction of pneumococcal conjugate vaccine. Pediatr Infect Dis J 27:1030-1032

71. Luján M, Gallego M, Belmonte Y, Fontanals D, Vallès J, Lisboa T, Rello J (2010) Influence of pneumococcal serotype group on outcome in adults with bacteraemic pneumonia. Eur Respir J 36:10731079

72. Bekri H, Cohen R, Varon E, Madhi F, Gire R, Guillot F et al (2007) Distribution des serotypes de pneumocoques responsables des pleuropneumopathies de l'enfant en France [Streptococcus pneumoniae serotypes involved in children with pleural empyemas in France]. Arch Pediatr 14:239-243

73. Byington CL, Korgenski K, Daly J, Ampofo K, Pavia A, Mason EO (2006) Impact of the pneumococcal conjugate vaccine on pneumococcal parapneumonic empyema. Pediatr Infect Dis J 25:250-254

74. Cillóniz C, Ewig S, Polverino E, Muñoz-Almagro C, Marco F, Gabarrús A et al (2012) Pulmonary complications of pneumococcal community-acquired pneumonia: incidence, predictors, and outcomes. Clin Microbiol Infect 18:1134-1142

75. Elemraid MA, Sails AD, Thomas MF, Rushton SP, Perry JD, Eltringham GJ et al (2013) Pneumococcal diagnosis and serotypes in childhood community-acquired pneumonia. Diag Microbiol Infect Dis 76:129-132

76. Ferrari CA, Pirez GM, Martínez AA, Algorta RG, Chamorro VF, Guala BM et al (2007) Etiology of community acquired pneumonia in inpatients children. Uruguay 1998-2004. Rev Chilena Infectol $24: 40-47$

77. Gendrel D, Lecarpentier T, Menager C, Harroche A, Leguillou S, Vallet $C$ et al (2011) Pneumococci isolated from vaccinated children with pneumonia. Arch Pediatr 18:518-521

78. González Martínez F, Saavedra Lozano J, Navarro Gómez ML, Santos Sebastián MM, Rodríguez Fernández R, González Sánchez $M$ et al (2013) Increase in the incidence of invasive pneumococcal disease caused by serotype 19A prior to the implementation of the expanded pneumococcal vaccines. An Pediatr (Barc) 79:288-292

79. Grisaru-Soen G, Eisenstadt M, Paret G, Schwartz D, Keller N, Nagar $H$ et al (2013) Pediatric parapneumonic empyema: risk factors, clinical characteristics, microbiology, and management. Pediatr Emerg Care 29:425-429

80. Hsieh Y-C, Hsiao C-H, Tsao P-N, Wang J-Y, Hsueh P-R, Chiang B$\mathrm{L}$ et al (2006) Necrotizing pneumococcal pneumonia in children: the role of pulmonary gangrene. Pediatr Pulmonol 41:623-629

81. Kanungo R, Rajalakshmi B (2001) Serotype distribution \& antimicrobial resistance in Streptococcus pneumoniae causing invasive \& other infections in south India. Indian J Med Res 114:127-132

82. Kendall BA, Dascomb KK, Mehta RR, Mason EO, Ampofo K, Pombo DJ et al (2011) Streptococcus pneumoniae serotypes in Utah adults at the end of the PCV7 era. Vaccine 29:9123-9126

83. Lai CY, Huang LM, Lee PY, Lu CY, Shao PL, Chang LY (2012) Comparison of invasive pneumococcal disease caused by serotype
19A and non-19A pneumococci in children: More empyema in serotype 19A invasive pneumococcal disease. J Microbiol Immunol Infect. pii: S1684-1182(12)00172-7. doi:10.1016/j.jmii. 2012.08.011

84. Maataoui N, Bidet P, Doit C, De Lauzanne A, Lorrot M, MarianiKurkdjian P et al (2011) A multiplex polymerase chain reaction method for rapid pneumococcal serotype determination in childhood empyema. Diagn Microbiol Infect Dis 69:245-249

85. Messina AF, Katz-Gaynor K, Barton T, Ahmad N, Ghaffar F, Rasko D, McCracken GH Jr (2007) Impact of the pneumococcal conjugate vaccine on serotype distribution and antimicrobial resistance of invasive Streptococcus pneumoniae isolates in Dallas, TX, children from 1999 through 2005. Pediatr Infect Dis J 26:461-467

86. Muñoz-Almagro C, Esteva C, de Sevilla MF, Selva L, Gene A, Pallares R (2009) Emergence of invasive pneumococcal disease caused by multidrug-resistant serotype 19A among children in Barcelona. J Infect 59:75-82

87. Obando I, Muñoz-Almagro C, Arroyo LA, Tarrago D, SanchezTatay D, Moreno-Perez D et al (2008) Pediatric parapneumonic empyema, Spain. Emerg Infect Dis 14:1390-1397

88. Obando I, Camacho-Lovillo MS, Porras A, Gandía-González MA, Molinos A, Vazquez-Barba I et al (2012) Sustained high prevalence of pneumococcal serotype 1 in paediatric parapneumonic empyema in southern Spain from 2005 to 2009. Clin Microbiol Infect 18:763768

89. Payeras A, Villoslada A, Garau M, Borras M, Pareja A, Beingolea D et al (2011) Pneumococcal pneumonia in the era of heptavalent pneumococcal conjugate vaccine. Enferm Infecc Microbiol Clin 29:250-256

90. Picazo J, Ruiz-Contreras J, Casado-Flores J, Negreira S, Del Castillo F, Hernández-Sampelayo T et al (2011) Laboratorybased, 2-year surveillance of pediatric parapneumonic pneumococcal empyema following heptavalent pneumococcal conjugate vaccine universal vaccination in Madrid. Pediatr Infect Dis J 30: 471-474

91. van Hoek AJ, Andrews N, Waight PA, George R, Miller E (2012) Effect of serotype on focus and mortality of invasive pneumococcal disease: coverage of different vaccines and insight into non-vaccine serotypes. PLoS One 7:e39150

92. Muñoz-Almagro C, Gala S, Selva L, Jordan I, Tarragó D, Pallares R (2011) DNA bacterial load in children and adolescents with pneumococcal pneumonia and empyema. Eur J Clin Microbiol Infect Dis 30: 327-335

93. Tarragó D, Fenoll A, Sánchez-Tatay D, Arroyo LA, MuñozAlmagro C, Esteva C et al (2008) Identification of pneumococcal serotypes from culture-negative clinical specimens by novel realtime PCR. Clin Microbiol Infect 14:828-834

94. Thomas MF, Sheppard CL, Guiver M, Slack MP, George RC, Gorton R et al (2012) Emergence of pneumococcal 19A empyema in UK children. Arch Dis Child 97:1070-1072

95. Esposito S, Marchese A, Tozzi AE, Rossi GA, Da Dalt L, Bona G et al (2013) DNA bacterial load in children with bacteremic pneumococcal community-acquired pneumonia. Eur J Clin Microbiol Infect Dis 32:877-881

96. Weigl JAI, Puppe W, Belke O, Neusüss J, Bagci F, Schmitt HJ (2005) Population-based incidence of severe pneumonia in children in Kiel, Germany. Klin Padiatr 217:211-219

97. Dortet L, Ploy MC, Poyart C, Raymond J; ORP Ile de France Ouest (2009) Emergence of Streptococcus pneumoniae of serotype 19A in France: molecular capsular serotyping, antimicrobial susceptibilities, and epidemiology. Diagn Microbiol Infect Dis 65:49-57

98. Payeras A, Villoslada A, Garau M, Borras M, Pareja A, Beingolea $\mathrm{D}$ et al (2011) Neumonía neumocócica en la era de la vacuna conjugada heptavalente. Enferm Infecc Microbiol Clin 29:250-256 
99. Fletcher M, Leeming J, Cartwright K, Finn A; South West of England Invasive Community Acquired Infection Study Group (2006) Childhood empyema: limited potential impact of 7-valent pneumococcal conjugate vaccine. Pediatr Infect Dis J 25:559560

100. Weinstein MP, Klugman KP, Jones RN (2009) Rationale for revised penicillin susceptibility breakpoints versus Streptococcus pneumoniae: coping with antimicrobial susceptibility in an era of resistance. Clin Infect Dis 48:1596-1600
101. Obando I, Arroyo LA, Sánchez-Tatay D, Moreno D, Hausdorff WP, Brueggemann AB (2006) Molecular typing of pneumococci causing parapneumonic empyema in Spanish children using multilocus sequence typing directly on pleural fluid samples. Pediatr Infect Dis J 25:962-963

102. Janapatla RP, Hsu MH, Hsieh YC, Lee HY, Lin TY, Chiu CH (2013) Necrotizing pneumonia caused by nanC-carrying serotypes is associated with pneumococcal haemolytic uraemic syndrome in children. Clin Microbiol Infect 19:480-486 